\title{
Drug-related problems in patients with rheumatoid arthritis
}

This article was published in the following Dove Medical Press journal:

Therapeutics and Clinical Risk Management

\author{
Shu Ning $\mathrm{Ma}^{\prime}$ \\ Hasniza Zaman Huri ${ }^{1,2}$ \\ Fariz Yahya ${ }^{3}$ \\ 'Department of Pharmacy, Faculty \\ of Medicine, University of Malaya, \\ Kuala Lumpur, Malaysia; ${ }^{2}$ Clinical \\ Investigation Centre, University of \\ Malaya Medical Centre, Kuala Lumpur, \\ Malaysia; ${ }^{3}$ Division of Rheumatology, \\ Department of Medicine, Faculty \\ of Medicine, University of Malaya, \\ Kuala Lumpur, Malaysia
}

\begin{abstract}
Background: Rheumatoid arthritis (RA) patients are at risk of acquiring drug-related problems (DRPs). However, there has been a lack of studies on DRPs in patients with RA up to now.

Method: This retrospective study was conducted in a tertiary hospital in Malaysia from January 2012 to December 2017 with the purpose of assessing DRPs in RA patients and factors associated with its occurrence. A total of 200 patients who had received pharmacological treatment for RA were enrolled in this study. Assessment of DRPs was based on the Pharmaceutical Network Care Europe tool version 5.01.
\end{abstract}

Results: A total of 289 DRPs with an average of $1.5 \pm 1.0$ problems per patient were identified, in which $78.5 \%$ of the population had at least one DRP. The most common DRPs encountered were adverse reactions (38.8\%), drug interactions (33.6\%), and drug-choice problems (14.5\%). Factors that had significant association with the occurrence of DRPs were polypharmacy $(P=0.003)$, multiple comorbidities $(P=0.001)$, hyperlipidemia $(P=0.009)$, osteo $(P=0.040)$, and renal impairment $(P=0.044)$. These data indicated that the prevalence of DRPs was high among RA patients. Conclusion: Early identification of types of DRPs and associated factors may enhance the prevention and management of RA.

Keywords: RA drugs, DRPs, factor associated, prevention and management

\section{Introduction}

Rheumatoid arthritis (RA) is a chronic autoimmune disease that gives rise to inflammation of joints, characterized by swelling and pain. ${ }^{1}$ RA can progress from self-limiting arthritis to irreversible joint destruction, and eventually to morbidity and disability. ${ }^{2}$ The prevalence of RA in Southeast Asia is $0.4 \%$, and is around $1 \%$ of the population worldwide. ${ }^{3,4}$ According to the Malaysian National Inflammatory Arthritis Registry, incidence is approximately double in female: $70 \%$ of RA patients are females. A study in the French West Indies has reported that the incidence of RA increases with age until around the eighth decade of life and declines thereafter. ${ }^{5}$

Symptoms and severity of RA can vary for each individual to a different extent. Some may experience mild--moderate forms with periods of flares and remission, while others may have severe forms, which stay active most of the time and last a lifetime. ${ }^{6}$ However, the specific causes of RA remain unclear. ${ }^{7}$ It is believed that a combination of genetic and environmental factors, such as female sex, family history, and exposure to tobacco smoke, are associated with the etiology of RA. ${ }^{4}$ Drug classes used to treat RA include nonsteroidal anti-inflammatory drugs (NSAIDs), disease-modifying antirheumatic drugs (DMARDs), and corticosteroids, the selection of drug depending on the severity of the disease. ${ }^{8}$

RA may lead to multiple complications and comorbidities, such as cardiovascular, pulmonary, and neuropsychiatric diseases, infection, and malignancy. ${ }^{9}$ The risk
Correspondence: Hasniza Zaman Hur Department of Pharmacy, Faculty of Medicine, University of Malaya, Kuala Lumpur 50603, Malaysia

Tel +6037967 6659

Fax +60 379674964

Email hasnizazh@um.edu.my 
of cardiovascular disease is higher by 1.5-fold to 2-fold in RA patients, due to systemic chronic inflammation of RA. ${ }^{10}$ According to a previous study, RA patients have two or more comorbidities on average. ${ }^{11}$ A recent nationwide survey in South Korea showed that the most frequently associated comorbidities in RA patients included hypertension $(30.3 \%)$, osteoarthritis (22.6\%), dyslipidemia (14.1\%), diabetes mellitus $(12.9 \%)$, and depression $(11.2 \%) .{ }^{12}$ The presence of comorbidities may affect the common outcome measures used specifically in RA, especially joint scores, remission and response criteria, and functional disability assessment. ${ }^{13}$ Furthermore, it will enhance the complexity of disease in patients with RA, which in turn poses the risk of acquiring drug-related problems (DRPs).

DRPs are events or circumstances involving drug therapy that actually or potentially interfere with desired health outcomes. ${ }^{14}$ There is a high incidence of DRPs in RA patients, such as drug-drug interactions, dosing problems, drug-choice problems, and adverse reactions. ${ }^{15}$ The incidence of DRPs is probably higher in elderly RA patients who receive multiple drugs to treat their comorbidities, resulting in polypharmacy and complex medication regimens. ${ }^{16}$ High inflammatory activity and long duration of treatment for chronic RA have also been shown to contribute to DRPs. ${ }^{16}$

In Malaysia, there have been studies done on DRPs in other diseases, including erectile dysfunction, benign prostatic hyperplasia, and diabetes mellitus. ${ }^{17-19}$ However, there has been a lack of studies on DRPs in patients with RA up to now. Currently, there are very limited data on DRPs in patients with RA in Malaysia. Owing to the potentially poor prognosis and susceptibility of acquiring DRPs that may affect quality of life, this study is crucial to provide additional data on the types and factors associated with DRPs in RA patients.

\section{Methods}

\section{Study design and setting}

This was a cross-sectional retrospective study conducted at the University of Malaya Medical Center (UMMC), a specialist tertiary hospital in Malaysia with approximately 1,300 beds, comprising 44 wards and serving around 1.7 million people in the Klang Valley area.

\section{Study population and sampling framework}

This study included a minimum sample of 95 patients, which was calculated by using Epi Info 7.0 (Centers for Disease Control and Prevention, Atlanta, GA, USA). In this program, the two-sided confidence level was set as $95 \%$, corresponding to a significance level $(\alpha)$ of 0.05 . The desired power $(1-\beta)$ of the study was fixed as $80 \%$. The expected proportion of RA patients was calculated based on the prevalence of RA, which is $1 \%$ worldwide. The study population consisted of all RA patients who fulfilled the requirements of the American College of Rheumatology (ACR)-European League Against Rheumatism (EULAR) 2010 criteria and CD10 code M05 and who had visited the UMMC from January 1, 2012 to December 31, 2017.

\section{Study procedures}

This study was in compliance with the Declaration of Helsinki, and it was approved by the medical ethics committee of the UMMC (20171030-5727). The committee waived the need for written informed consent from patients. Patient records were anonymized and deidentification of data done preceding analysis. The list of RA patients that fulfilled the ACR-EULAR 2010 criteria and ICD10 classification was retrieved from patient-information records of the UMMC. Patients were then screened for fulfillment of inclusion criteria based on the Ipesakit database. Thereafter, all relevant data stipulated in the data-collection form were collected from patients' electronic medical records. As this retrospective study was highly dependent on medical records as the only source of data, assessment of causality associated with DRPs was less robust. Figure 1 shows an overview of methodology.

Inclusion criteria were patients 18 years old and above, diagnosed with RA, and had received at least one medication indicated for RA. Exclusion criteria were patients with missing data, diagnosed with RA, but had not received any pharmacological treatment, and diagnosed with RA, but had received only nonpharmacological or complementary alternative medicines.

\section{Data collection}

Data collected were demographic information, such as age at diagnosis, age at initiation of RA treatment, sex, ethnicity, weight, height, body-mass index, and smoking and alcoholconsumption status; clinical characteristics, such as duration of hospitalization, time from RA diagnosis, RA extra-articular manifestation, complications, and comorbidities; laboratory results, including CRP, erythrocyte-sedimentation rate, and other monitoring parameters stated in medical folders; medications used in the treatment of RA, including corticosteroids, conventional synthetic DMARDs (csDMARDs), biological DMARDs, and other concurrent medications. Assessment of DRPs was based on the Pharmaceutical Care Network Europe (PCNE) classification version 5.01 and definitions of terms are given in Table 1. 


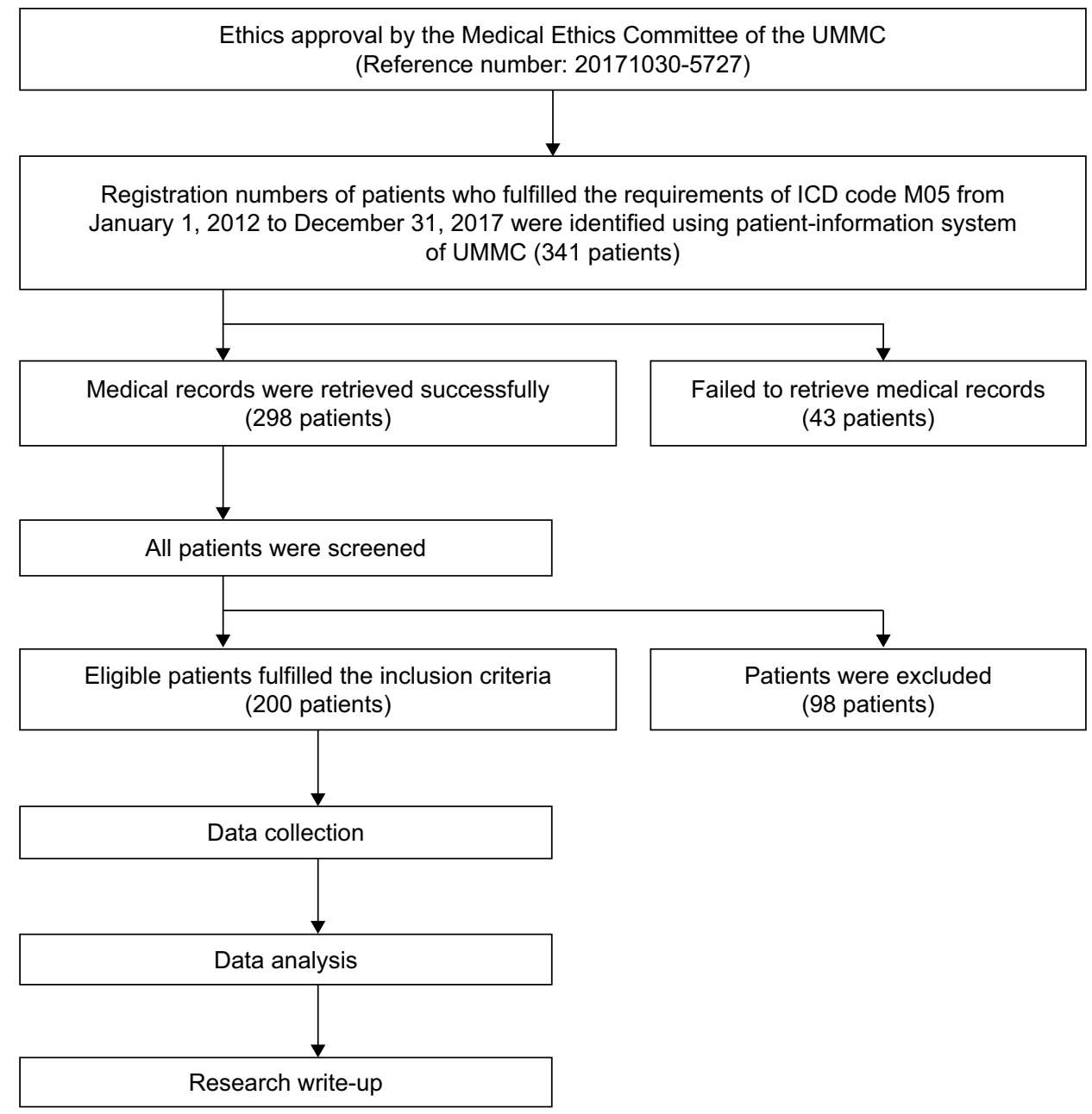

Figure I Overview of methodology.

Abbreviation: UMMC, University of Malaya Medical Centre.

\section{Classification and assessment of DRPs}

DRPs were categorized using PCNE classification version 5.01. The version used has been validated, is adapted regularly, and is compatible with previous versions. This classification was the most suitable tool to match the study objective and methodology, and hence was used in this study to assess problems, causes, and interventions associated with DRPs. Basically there are six primary domains with 21 subdomains for problems, six primary domains with 33 subdomains for causes, and five primary domains with

Table I Definition of terms

\begin{tabular}{|c|c|}
\hline & Definition \\
\hline Sjögren's syndrome & $\begin{array}{l}\text { A chronic autoimmune condition attacking in particular the tear and salivary glands, characterized by degeneration of } \\
\text { the salivary and lachrymal glands, causing dryness of the mouth and eyes }{ }^{20}\end{array}$ \\
\hline Hallux valgus & $\begin{array}{l}\text { A progressive foot deformity in which the first metatarsophalangeal joint is affected and often accompanied by } \\
\text { significant functional disability and foot pain }{ }^{21}\end{array}$ \\
\hline Lung fibrosis & $\begin{array}{l}\text { A lung disease where healthy tissue is replaced by altered extracellular matrix and alveolar architecture is destroyed, } \\
\text { which leads to decreased lung compliance, disrupted gas exchange, and ultimately respiratory failure and death }{ }^{22}\end{array}$ \\
\hline Elderly & People aged 65 years and above ${ }^{23}$ \\
\hline Polypharmacy & The use of five or more medications ${ }^{24}$ \\
\hline Renal impairment & $\begin{array}{l}\text { A condition that includes acute kidney injury, which refers to the sudden and rapid reduction of renal functions, over } \\
\text { hours to days, as well as chronic kidney injury, which refers to the deterioration of kidney functions for }>3 \text { months, } \\
\text { or as stated in the medical records }{ }^{25}\end{array}$ \\
\hline Hepatic impairment & $\begin{array}{l}\text { Refers to alcoholic or nonalcoholic liver cirrhosis, drug-induced hepatotoxicity, chronic hepatitis, liver cancer, increase } \\
\text { of serum liver enzymes more than three times the normal upper limits, or as stated in the medical records }{ }^{26}\end{array}$ \\
\hline
\end{tabular}


17 subdomains for interventions. ${ }^{14}$ The classification is useful in research related to DRPs, as it acts as a process indicator in studies of pharmaceutical care outcomes. In this study, we screened data and information from patients' medication records to identify DRPs and their possible causes. Other than that, by referring to standard guidelines and literature reviews, we assessed such DRPs as adverse reactions, drugchoice problems, dosing problems, drug-use problems, and possible drug interactions. The authors (clinical pharmacist and rheumatologist) were involved in the identification and classification of DRPs.

\section{Updated Beers criteria}

The 2015 American Geriatrics Society Beers criteria consist of lists of medications that are potentially inappropriate to be used among elderly patients. Lists of medications comprise drugs that should be avoided or have their dose adjusted in certain conditions, like kidney failure in geriatrics. In this study, the Beers criteria served as a tool to assess the appropriateness of medications used in RA patients for the items included under the domain of drug-choice problems in PCNE version 5.01 .

\section{Statistical techniques}

All collected and extracted data were analyzed with SPSS version 23.0 (IBM, Armonk, NY, USA). For categorical data, nominal and ordinal data are expressed as frequency or percentage. Frequency tables were used to tabulate and present such data as demographic and clinical characteristics of RA patients, different types of DRPs, and causes of DRPs. Other than frequency tables, categorical data are presented as bar charts as well. Associations between two categorical variables, such as patients' characteristics and occurrence of DRPs, are indicated by Pearson's $\chi^{2}$ test and logistic regression. Fisher's exact test was used for a two-by-two table if expected counts were fewer than five. Statistical significance was assumed at $P<0.05$.

\section{Results \\ Demographic characteristics}

A total of 200 patients were enrolled in this study. There were 1,532 cases derived from patients, which comprised 361 admissions and 1,171 follow-ups to the hospital. As shown in Figure 2, the majority of the patients belonged to the age-group of 60-69 years. Ages of the study population ranged from 22 to 91 years, with the median age of 64 (IQR 15) years.

Table 2 shows the demographic characteristics of this study population. Nonelderly patients were present in an almost-equal proportion as elderly patients: only $4 \%$ greater. The number of female patients (86\%) was five times higher than male patients (14\%). Indian was the most popular ethnic group, making up $40.5 \%$ of the population, followed by Malay, Chinese, and others. For body-mass index, only $16.5 \%$ of the data were retrievable. Social history of smoking and alcohol were available in only $20 \%$ and $10 \%$ of the study population, respectively.

\section{Clinical characteristics}

Around half the study population (51\%) had RA for $<10$ years. Sjögren's syndrome contributed to the highest percentage $(10 \%)$ among RA complications, followed by lung fibrosis (5.5\%). On average, each patient had 3.1 1.8 comorbidities, ranging from one to eight diseases. More than

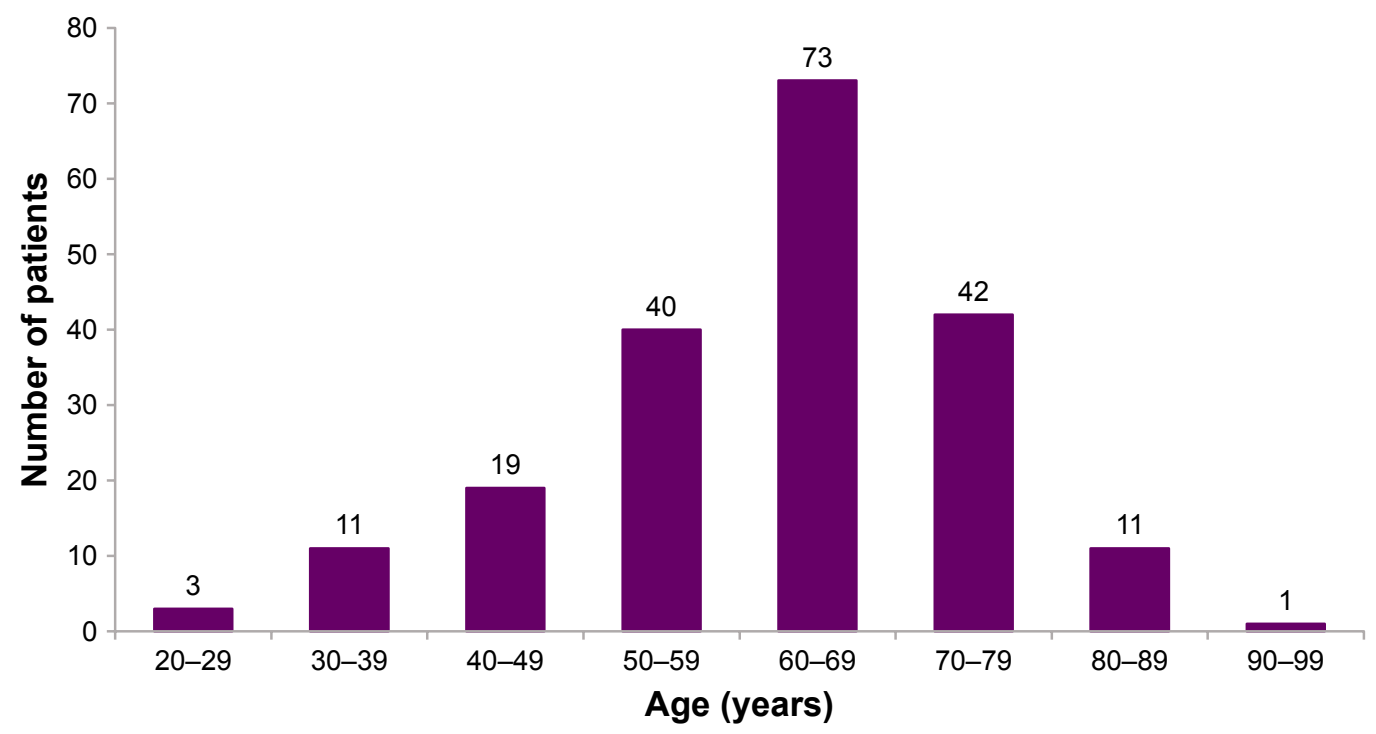

Figure 2 Age-groups of study population (years, $n=200$ ). 
Table 2 Demographic characteristics of study population $(n=200)$

\begin{tabular}{|c|c|c|c|}
\hline & $\begin{array}{l}\text { Total, n (\%) } \\
200 \text { (1 } 00 \%)\end{array}$ & $\begin{array}{l}\text { With DRP, n (\%) } \\
\text { I } 57(78.5 \%)\end{array}$ & $\begin{array}{l}\text { No DRP, n (\%) } \\
43(21.5 \%)\end{array}$ \\
\hline $\begin{array}{l}\text { Age (years), mean } \pm S D \\
\text { Population }\end{array}$ & $62.1 \pm 12.5$ & $62.6 \pm 13.0$ & $60.2 \pm 10.5$ \\
\hline Nonelderly & $104(52.0)$ & 78 (49.7) & $26(60.5)$ \\
\hline Elderly & $96(48.0)$ & $79(50.3)$ & $17(39.5)$ \\
\hline \multicolumn{4}{|l|}{ Sex } \\
\hline Male & $28(14.0)$ & $24(15.3)$ & $4(9.3)$ \\
\hline Female & $172(86.0)$ & $133(84.7)$ & $39(90.7)$ \\
\hline \multicolumn{4}{|l|}{ Ethnicity } \\
\hline Malay & $58(29.0)$ & 47 (29.9) & II (25.6) \\
\hline Chinese & $57(28.5)$ & $48(30.6)$ & $9(20.9)$ \\
\hline Indian & $81(40.5)$ & $58(36.9)$ & $23(53.5)$ \\
\hline Others & $4(2.0)$ & $4(2.5)$ & 0 \\
\hline \multicolumn{4}{|l|}{ BMI } \\
\hline Underweight $(<18.5)$ & 0 & 0 & 0 \\
\hline Normal range (I8.5-24.9) & $14(7.0)$ & $14(8.9)$ & 0 \\
\hline Overweight (25.0-29.9) & $9(4.5)$ & $7(4.5)$ & $2(4.7)$ \\
\hline Obese $(\geq 30.0)$ & $10(5.0)$ & $9(9.7)$ & $\mathrm{I}(2.3)$ \\
\hline Unknown & $167(83.5)$ & $127(80.9)$ & $40(93.0)$ \\
\hline \multicolumn{4}{|l|}{ Smoking } \\
\hline Nonsmoker & $10(5.0)$ & $7(4.5)$ & $3(7.0)$ \\
\hline Smoker & $8(4.0)$ & $6(3.8)$ & $2(4.7)$ \\
\hline Ex-smoker & $2(1.0)$ & $2(1.3)$ & 0 \\
\hline Unknown & $180(90.0)$ & $142(90.4)$ & $38(88.4)$ \\
\hline \multicolumn{4}{|l|}{ Alcohol } \\
\hline No & $8(4.0)$ & $5(3.2)$ & $3(7.0)$ \\
\hline Yes & $2(1.0)$ & $\mathrm{I}(0.6)$ & $\mathrm{I}(2.3)$ \\
\hline Ex-drinker & 0 & 0 & 0 \\
\hline Unknown & $190(95.0)$ & $|5|$ (96.2) & $39(90.7)$ \\
\hline
\end{tabular}

Note: $\mathrm{BMI}=$ weight $(\mathrm{kg}) /($ height $[\mathrm{m}] \times$ height $[\mathrm{m}])$.

Abbreviations: BMI, body mass index; DRP, drug-related problem.

half the population (56.5\%) had three or more comorbidities. Hyperlipidemia and hypertension were the top two comorbidities, found in $56 \%$ and $55 \%$ of patients, respectively. Approximately a third of the patients (33\%) had comorbid type 2 diabetes mellitus, $27.5 \%$ suffered from osteoarthritis, and $25.5 \%$ had osteoporosis. Only $4 \%$ of the population had no comorbidities. Approximately two-thirds (64.5\%) of patients were found to have polypharmacy, which involved $74 \%$ of the elderly population. The mean number of medications received by each patient was $5.5 \pm 2.3$, ranging from 1 to 12 (Table 3 ).

\section{Medications used in study population RA medications}

In this study, csDMARD monotherapy was the most commonly prescribed for RA patients, which involved the single use of such csDMARDs as methotrexate (Mtx), sulfasalazine, hydroxychloroquine, or leflunomide. As shown in Figure 3, approximately $60 \%$ of the patient population received csDMARD monotherapy. Double-csDMARD therapy was used in around a quarter of the patients, followed by $<10 \%$ of the population who received triple-csDMARD therapy. In contrast, the use of biologics and immunosuppressive drugs was less common, representing $1.0 \%$ and $0.5 \%$, respectively.

Among DMARDs, Mtx was the most frequently prescribed. As shown in Table 4, 133 of the 200 patients $(66.5 \%)$ received Mtx for RA treatment. The most common dose of Mtx was $7.5 \mathrm{mg}$ per week (15\%), followed by $10 \mathrm{mg}$ per week (13\%). Approximately a third of the patients (32.5\%) were treated with sulfasalazine, and the most widely prescribed dose was 1,000 mg per day (14.5\%). Hydroxychloroquine was more commonly used than leflunomide, with a difference of $17 \%$. In terms of dosing, hydroxychloroquine $400 \mathrm{mg}$ per day was among the most commonly prescribed dose compared to other dosing, comprising $19 \%$ of the patient population.

There were four drugs used as adjunctive therapy in the study population. About $50 \%$ of the population received prednisolone as an adjunct. Of the 99 patients who received prednisolone, 
Table 3 Clinical characteristics of study population $(n=200)$

\begin{tabular}{|c|c|c|c|}
\hline & \begin{tabular}{|l|} 
Total, n (\%) \\
200 (100\%)
\end{tabular} & $\begin{array}{l}\text { With DRP, n (\%) } \\
\text { I } 57 \text { (78.5\%) }\end{array}$ & $\begin{array}{l}\text { No DRP, n (\%) } \\
43(21.5 \%)\end{array}$ \\
\hline \multicolumn{4}{|l|}{ Duration of RA } \\
\hline$<10$ years & $102(5 \mathrm{I} .0)$ & $77(49.0)$ & $25(58.1)$ \\
\hline$\geq 10$ years & $82(41.0)$ & $67(42.7)$ & $15(34.9)$ \\
\hline Unknown & $16(8.0)$ & $13(8.3)$ & $3(7.0)$ \\
\hline \multicolumn{4}{|l|}{ RA complications } \\
\hline Lung fibrosis & II (5.5) & $10(6.4)$ & I (2.3) \\
\hline Sjögren's syndrome & $20(10.0)$ & $6(3.8)$ & $4(9.3)$ \\
\hline Leg abscess & $2(1.0)$ & $2(1.3)$ & 0 \\
\hline Hallux valgus & $2(1.0)$ & $2(1.3)$ & 0 \\
\hline \multicolumn{4}{|l|}{ Number of comorbidities } \\
\hline$<3$ & $87(43.5)$ & $58(36.9)$ & $29(67.4)$ \\
\hline$\geq 3$ & $113(56.5)$ & $99(63.1)$ & $14(32.6)$ \\
\hline \multicolumn{4}{|l|}{ Comorbidities } \\
\hline Hyperlipidemia & $112(56.0)$ & $96(61.1)$ & $16(37.2)$ \\
\hline Hypertension & $110(55.0)$ & $92(58.6)$ & $18(4 \mid .8)$ \\
\hline Type 2 diabetes & $66(33.0)$ & $52(33.1)$ & $14(32.5)$ \\
\hline Osteoarthritis & $55(27.5)$ & $49(31.2)$ & $6(14.0)$ \\
\hline Osteoporosis & $51(25.5)$ & $46(29.3)$ & $5(11.6)$ \\
\hline Cardiovascular disease & $33(16.5)$ & $28(17.8)$ & $5(11.6)$ \\
\hline Anemia & $24(12.0)$ & $17(10.8)$ & $7(16.3)$ \\
\hline Asthma & $23(11.5)$ & $17(10.8)$ & $6(14.0)$ \\
\hline Renal impairment & $15(7.5)$ & $15(9.6)$ & 0 \\
\hline Hypothyroidism & $14(7.0)$ & $10(6.4)$ & $4(9.3)$ \\
\hline Hepatic impairment & $13(6.5)$ & $10(6.4)$ & $3(7.0)$ \\
\hline Psychological disorder & $6(3.0)$ & $5(3.2)$ & I (2.3) \\
\hline Cancer & $6(3.0)$ & $3(1.9)$ & $3(7.0)$ \\
\hline \multicolumn{4}{|l|}{ Polypharmacy } \\
\hline Yes & $129(64.5)$ & $110(70.1)$ & $19(44.2)$ \\
\hline No & 7I (35.5) & 47 (29.9) & $24(55.8)$ \\
\hline
\end{tabular}

Note: Patients may have had no or more than one RA complication or comorbidity.

Abbreviations: DRP, drug-related problem; RA, rheumatoid arthritis.

$80 \%$ had been prescribed the drug at the most common dose of $5 \mathrm{mg}$ per day. Among painkillers, NSAIDs were preferable to be prescribed (28.5\%) compared to paracetamol and tramadol, with common use of celecoxib $200 \mathrm{mg}$ per day.

\section{Concurrent medications}

Several classes of drugs were reported to be commonly used in the study population. Figure 4 reveals the top ten concurrent medications with the highest percentage frequency.

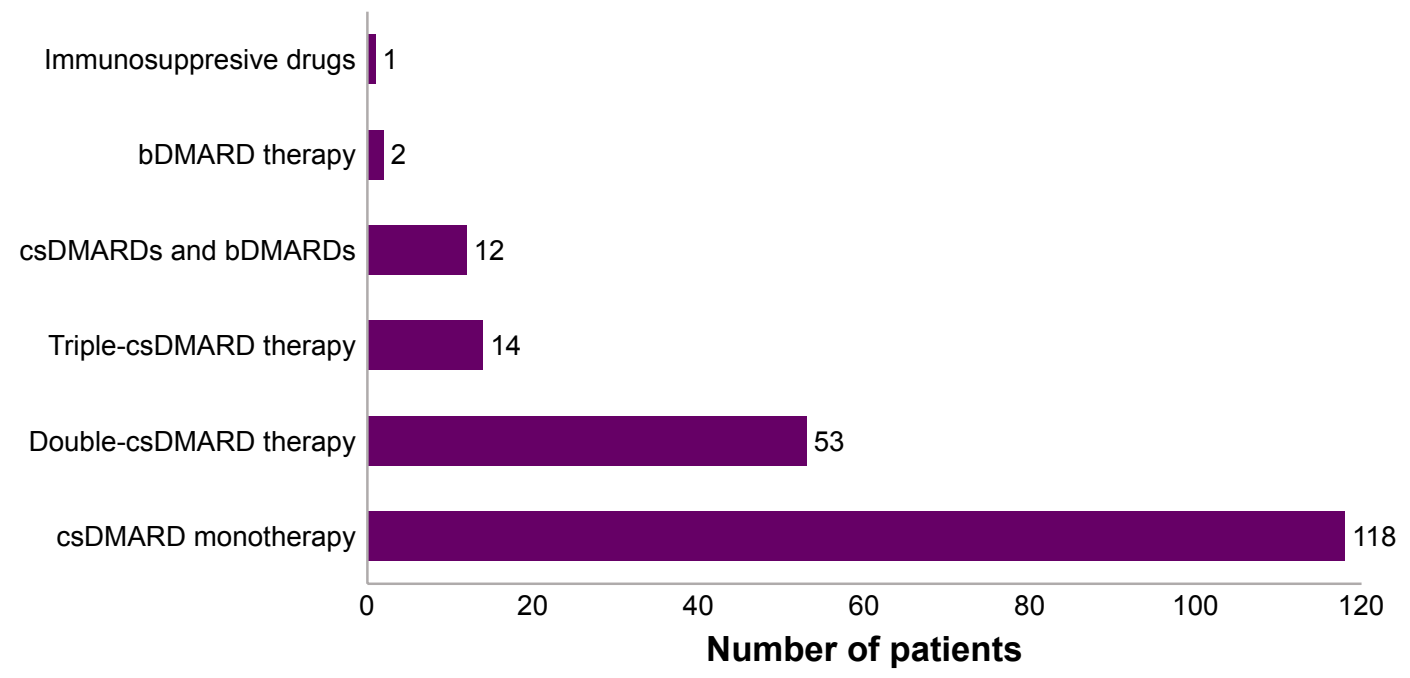

Figure 3 Drug categories used in patients $(\mathrm{n}=200)$.

Abbreviations: bDMARD, biological disease-modifying antirheumatic drug; csDMARDs, conventional synthetic DMARDs. 
Table 4 DMARDs commonly used in RA patients $(n=200)^{a}$

\begin{tabular}{l|l|l}
\hline & Dose (mg) & Patients, $\mathbf{n}(\%)$ \\
\hline Methotrexate $^{b}$ & 2.5 & $3(1.5)$ \\
$\mathrm{n}=133(66.5 \%)$ & 5.0 & $5(2.5)$ \\
& 7.5 & $30(15.0)$ \\
& 10.0 & $26(13.0)$ \\
& 12.5 & $25(12.5)$ \\
& 15.0 & $25(12.5)$ \\
& 17.5 & $9(4.5)$ \\
& 20.0 & $9(4.5)$ \\
Sulfasalazine & & 0 \\
$\mathrm{n}=65(32.5 \%)$ & 22.5 & $1(0.5)$ \\
& 25.0 & $7(3.5)$ \\
Hydroxychloroquine & 500 & $29(14.5)$ \\
$\mathrm{n}=58(29.0 \%)$ & 1,000 & $23(11.5)$ \\
Leflunomide $^{c}$ & 2,000 & $6(3.0)$ \\
$\mathrm{n}=24$ (I2.0\%) & 3,000 & $20(10.0)$ \\
\hline
\end{tabular}

Notes: aPatients may have received more than one DMARD; bdose received by patient per week; ' dose received by patient per day.

Abbreviations: DMARDs, disease-modifying antirheumatic drugs; RA, rheumatoid arthritis.

Statins were the most frequently implicated drug class, and had been prescribed in $>50 \%$ of the patients. Among statins, simvastatin $20 \mathrm{mg}$ was the most common, as it had been used in approximately $82 \%$ of 109 patients who received statins as a lipid-lowering agent. Gastroprotective agents were prescribed in about a third (33.5\%) of the study population, including $28 \%$ proton-pump inhibitors and $5.5 \%$ $\mathrm{H}_{2}$ antagonists. The most common antidiabetic drug prescribed in the study was metformin, either as monotherapy or combination therapy, received by more than a quarter of the patients $(26 \%)$.

For antihypertensive agents, calcium-channel blockers were found to be most commonly prescribed, prescribed in approximately $30 \%$ of the study population. These were followed by angiotensin-converting enzyme inhibitors, $\beta$-blockers, diuretics and angiotensin-receptor blockers, while $\alpha$-blockers, such as prazosin, were the least commonly prescribed antihypertensive agent, used by only $3 \%$ of the study population. Antibiotics were used in $10.5 \%$ of the patient population, with amoxicillin the most commonly prescribed, representing $75 \%$ of patients who received antibiotics.

\section{Drug-related problems}

A total of 289 DRPs were identified in the 200 patients. On average, each patient had $1.5 \pm 1.0$ problems with $1.5 \pm 1.0$ causes. The number of DRPs in the patients ranged from zero to five. A total of 157 patients $(78.5 \%)$ were detected with at least one DRP. As shown in Figure 5, the top two domains of DRPs were adverse reactions (38.8\%) and interactions $(33.6 \%)$ in which both accounted for more than a third of the population. This was followed by drug-choice problems (14.5\%), drug-use problems (7.6\%) and dosing problems

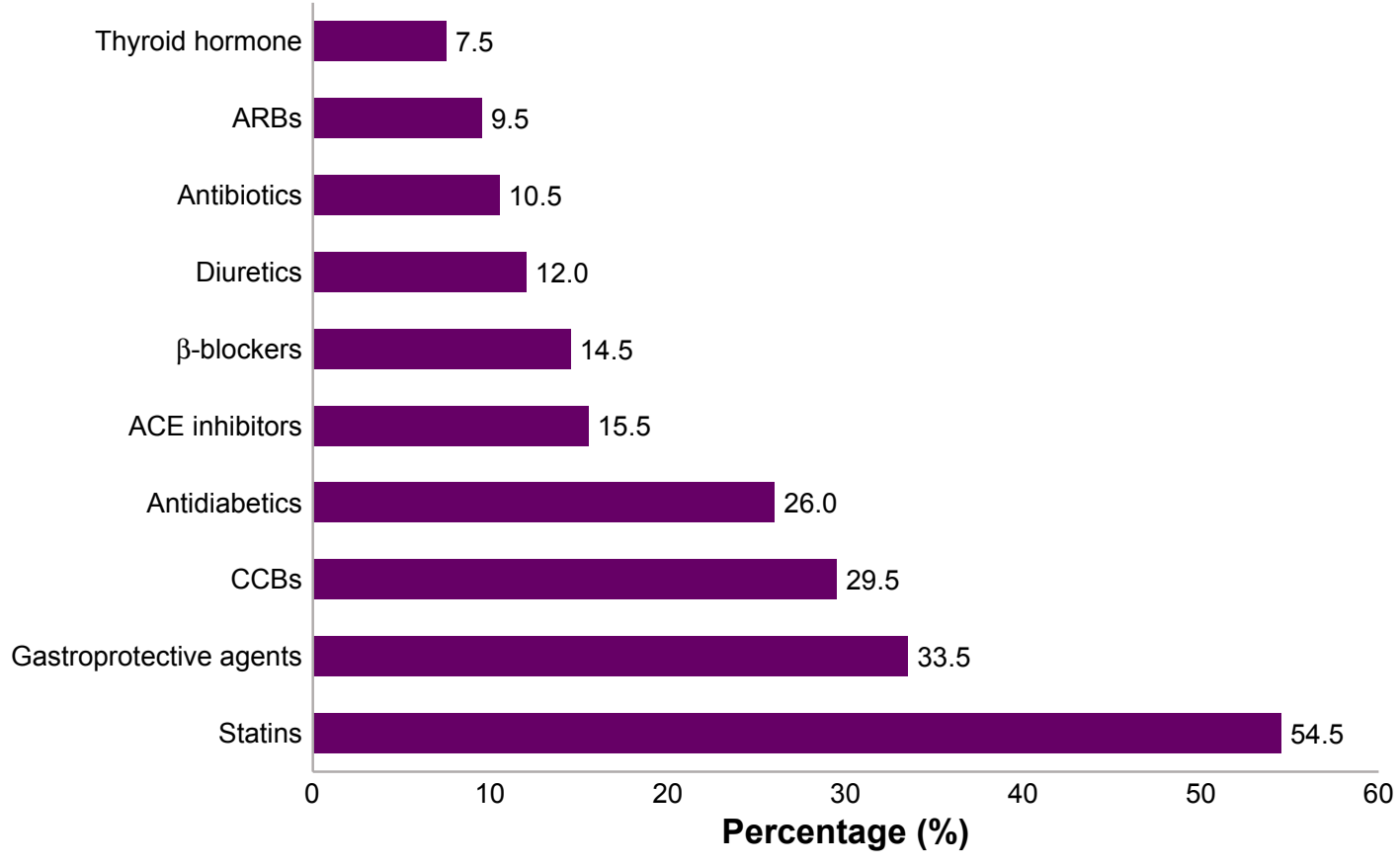

Figure 4 Classes of concurrent medications $(n=200)$.

Note: Patients may have had more than one concurrent medication.

Abbreviations: ARBs, angiotensin-receptor blockers; CCBs, calcium-channel blockers. 


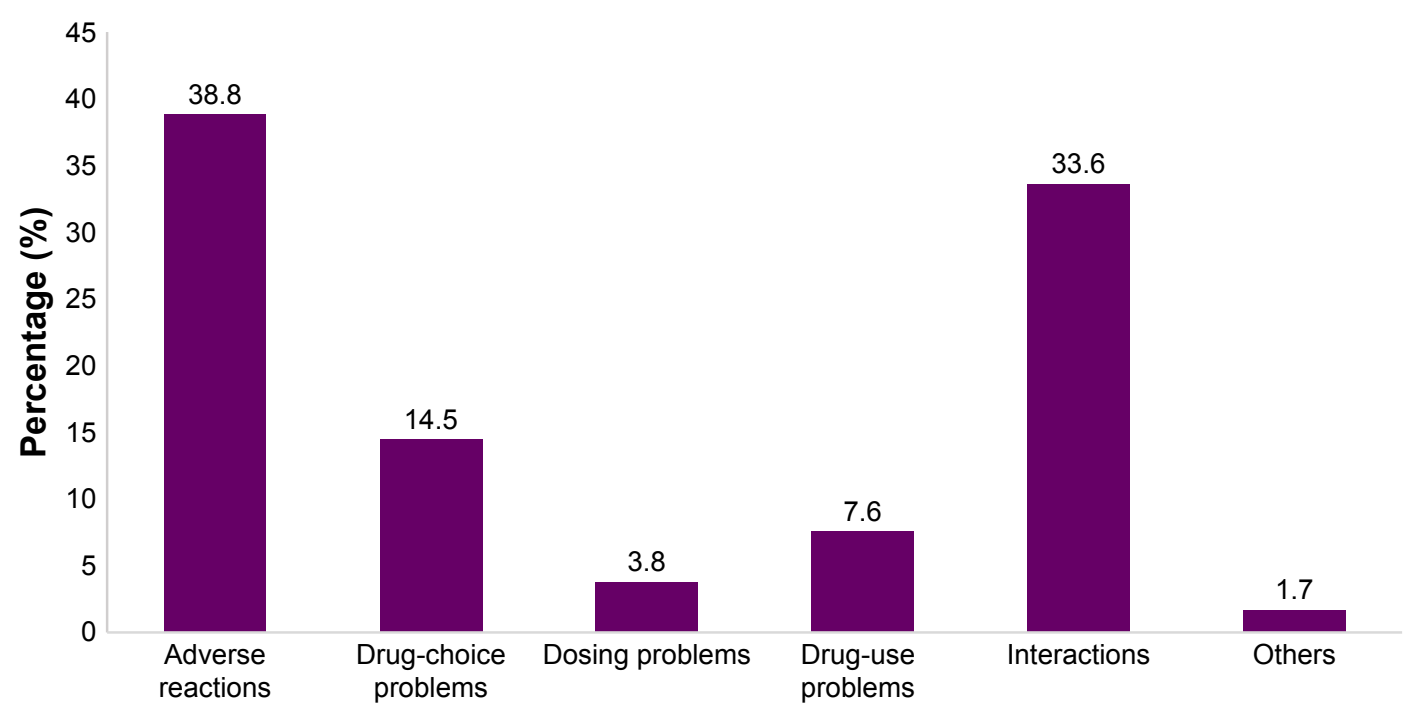

Figure 5 Drug-related problems $(n=289)$.

(3.8\%). Other domains had the lowest incidence, making up only $1.7 \%$ of all DRPs.

\section{Adverse reactions}

A total of 112 cases of adverse reactions were identified, including nonallergic, allergic, and toxic effects of drugs (Table 5). Most adverse reactions were associated with the use of DMARDs, especially Mtx. For nonallergic side effects, there were 19 cases reported with the use of Mtx that resulted in myelosuppression, including pancytopenia, bicytopenia, leukopenia, neutropenia, and thrombocytopenia. Gastrointestinal disturbances secondary to Mtx occurred in 17 patients, comprising nausea, vomiting, diarrhea, and epigastric pain. Elevated levels of liver enzymes associated with Mtx were reported as transaminitis in 14 cases, and hepatitis was experienced by six patients. There were seven cases of pneumonitis reported in patients receiving Mtx, and four patients developed lung fibrosis. Oral ulcers were also reported as side effects of Mtx in four cases. One patient complained of alopecia after receiving Mtx. Also, sulfasalazine caused neutropenia, nausea, vomiting, and diarrhea. Hydroxychloroquine was associated with blurred vision and maculopathy, whereas leflunomide was reported to cause cardiomyopathy in one case.

Table 5 Adverse reactions $(n=289)$

\begin{tabular}{l|l|l}
\hline Code & Problem & n (\%) \\
\hline PI & Adverse reactions & $\mathrm{II} 2(38.8)$ \\
PI.I & Side effect suffered (nonallergic) & $96(33.2)$ \\
PI.2 & Side effect suffered (allergic) & I5 (5.2) \\
PI.3 & Toxic effect suffered & $\mathrm{I}(0.3)$ \\
\hline
\end{tabular}

Note: Only problems with frequency of one or more were included.
For allergic side effects, rash attributed to the use of Mtx, sulfasalazine, leflunomide, and infliximab was reported in seven cases. Dermatitis due to Mtx, hydroxychloroquine, and adalimumab was also reported. There was one patient that suffered from acute generalized erythematous pustulosis caused by sulfasalazine. All adverse reactions were diagnosed by clinical suspicion and interpreted from clinical findings and history. As such, associations between drugs and adverse reactions could not be completely verified.

\section{Drug-choice problems}

As shown in Table 6, inappropriate drug choice and untreated indications were the two most commonly detected drugchoice problems. There were 25 cases where no drugs were given, despite clear indications. For instance, hyperlipidemia was left untreated in eleven cases, persistently high blood pressure in seven, and four cases showed no treatment was given for symptomatic anemia.

According to updated Beers criteria, several drugs prescribed for elderly patients were considered inappropriate and high risk in this study, which accounted for most of the problems of inappropriate drug choice identified, including

Table 6 Drug-choice problems $(n=289)$

\begin{tabular}{l|l|l}
\hline Code & Problem & n (\%) \\
\hline P2 & Drug-choice & $42(14.5)$ \\
P2.1 & Inappropriate drug & $12(4.2)$ \\
P2.3 & Inappropriate duplication of therapeutic & $2(0.7)$ \\
& group or active ingredient & \\
P2.4 & Contraindication for drug & $3(1.0)$ \\
P2.6 & No drug prescribed, but clear indication & $25(8.7)$ \\
\hline
\end{tabular}

Note: Only problems with frequency of one or more were included. 
Table 7 Dosing problems $(n=289)$

\begin{tabular}{l|l|l}
\hline Code & Problem & n (\%) \\
\hline P3 & Dosing & I I (3.8) \\
P3.I & $\begin{array}{l}\text { Drug dose too low or dosage regime not } \\
\text { frequent enough }\end{array}$ & $2(0.7)$ \\
P3.2 & $\begin{array}{l}\text { Drug dose too high or dosage regime too } \\
\text { frequent }\end{array}$ & $8(2.8)$ \\
P3.3 & Duration of treatment too short & $\mathrm{I}(0.3)$ \\
\hline
\end{tabular}

Note: Only problems with frequency of one or more were included.

diphenhydramine (four cases), chlorpheniramine (two cases), ticlopidine (three cases), amitriptyline (two cases), and nifedipine (one case). There was also one case where NSAIDs were prescribed in an elderly patient with chronic kidney disease (CKD). There were three cases associated with the use of contraindicated drugs. For example, Mtx was prescribed for a patient despite poor renal function, indicated by low creatinine clearance, which was $<20 \mathrm{~mL} / \mathrm{min}$. Inappropriate duplication of drugs was detected in two cases, involving the concurrent use of two NSAIDs: celecoxib and diclofenac.

\section{Dosing problems}

Among the eleven cases of dosing problems, there were eight identified with medication overdoses (Table 7). Drugs involved were simvastatin (two cases), ranitidine (two cases), and cotrimoxazole (one case). Prescription of drugs at excessive doses was most commonly detected in patients with existing renal impairment, comprising $>90 \%$ of cases. Also, RA medications, such as hydroxychloroquine, were associated with two cases of overdose, which exceeded the maximum dose of $6.5 \mathrm{mg} / \mathrm{kg}$ per day. There was one case where Mtx was prescribed with an initial dose of $20 \mathrm{mg}$ instead of $7.5 \mathrm{mg}$.

\section{Drug-use problems}

There were 22 cases of drug-use problems detected, and all were recorded in the patients' medical records as drugs having not been taken or administered at all (Table 8). Mtx was implicated in $50 \%$ of all drug-use problems, followed by sulfasalazine (three cases), hydroxychloroquine (two cases), and leflunomide (one case). Noncompliance with other medications was also reported, including statins, antihypertensive agents, antidiabetic drugs, and alendronate.

Table 8 Drug-use problems $(n=289)$

\begin{tabular}{l|l|l}
\hline Code & Problem & n (\%) \\
\hline P4 & Drug use & $22(7.6)$ \\
P4.I & Drug not taken/administered at all & $22(7.6)$ \\
\hline
\end{tabular}

Note: Only problems with frequency of one or more were included.

\section{Drug interactions}

About a third of all DRPs identified were related to drug interactions (Table 9). Approximately $70 \%$ of cases of drug interaction involved DMARDs used in RA treatment, such as Mtx and sulfasalazine. The concurrent use of prednisolone and simvastatin posed a significant potential drug interaction in 39 cases. As shown in Figure 6, the drug most implicated in drug interactions was Mtx (89 cases), which interacted with omeprazole (34 cases), diclofenac (31 cases), aspirin (12 cases), amoxicillin (11 cases), and hydrochlorothiazide ( 1 case). This was followed by sulfasalazine, involved in 17 cases. In addition, there were 2 cases in which patients were prescribed simvastatin at $>20 \mathrm{mg}$ while receiving amlodipine.

\section{Other problems}

Among all 289 DRPs identified in this study, $1.7 \%$ were problems that could not be classified under any domain, which were regarded as "others" (Table 10). A total of five cases were associated with insufficient awareness of health and diseases, possibly leading to future problems. For instance, some patients had a lack of knowledge on RA, which made them unaware of the importance of treatment, resulting in defaults on follow-up. There was one patient who was reported with chronic use of diclofenac, in which the drug was taken daily even when they did not feel any pain, instead of being used when necessary.

\section{Causes of DRPs}

Table 11 shows a total of 289 causes for DRPs. Among all the six domains of causes, "others" and "drug or dose selection" were found to be the two most common, which comprised $47.1 \%$ and $43.3 \%$, respectively, followed by "patient or psychological" ( $8.3 \%)$. For subtypes, the three most common causes were "no obvious cause" under the domain of "others", "manifest side effect with no other causes", and "inappropriate drug selection", both under the domain of "drug or dose selection".

\section{Factors associated with DRPs}

Table 12 shows the parameters that were significantly associated with the occurrence of DRPs in patients with RA.

Table 9 Drug interactions $(n=289)$

\begin{tabular}{l|l|l}
\hline Code & Problem & n (\%) \\
\hline P5 & Interactions & $97(33.6)$ \\
P5. I & Potential interaction & $96(33.2)$ \\
P5.2 & Manifest interaction & $\mathrm{I}(0.3)$ \\
\hline
\end{tabular}

Note: Only problems with frequency of one or more were included. 


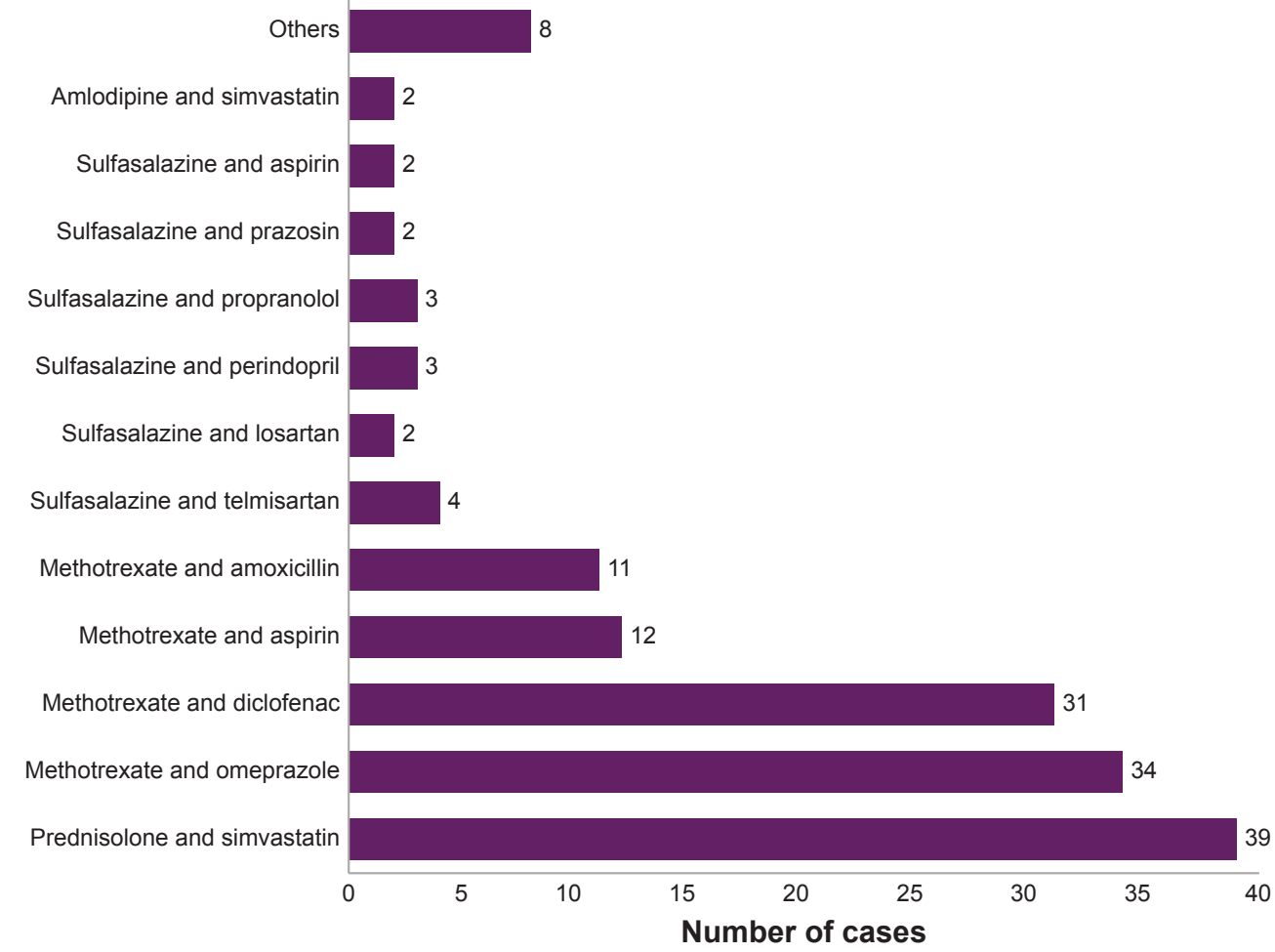

Figure 6 Drug pairs associated with drug interactions ( $n=97)$.

Note: A drug-related problem identified may have involved more than one pair of drug interactions.

Polypharmacy $(P=0.005)$ and multiple comorbidities $(P=0.001)$ appeared to have significant associations with the occurrence of DRPs. Apart from that, several concurrent chronic diseases, such as hyperlipidemia $(P=0.009)$, osteoarthritis $(P=0.040)$, and renal impairment $(P=0.044)$, were associated significantly with the DRPs identified. On the other hand, factors that had no significant association with the occurrence of DRPs included RA complications such as lung fibrosis and Sjögren's syndrome and comorbidities such as hypertension, type 2 diabetes mellitus, cardiovascular diseases, and hepatic impairment.

Tables 13-15 tabulate the associations between different factors and the six domains of DRPs. It was found that there were significant associations between the occurrence of adverse drug reactions and such parameters as multiple comorbidities $(P=0.038)$ and renal impairment $(P=0.022)$. There was only one factor - renal impairment $(P=0.027)$ - associated significantly with drug-choice problems. Patients with type 2 diabetes mellitus $(P=0.017)$

Table 10 Other problems $(\mathrm{n}=289)$

\begin{tabular}{l|l|l}
\hline Code & Problem & $\mathbf{n ~ ( \% )}$ \\
\hline P6 & Others & $5(1.7)$ \\
P6.2 & $\begin{array}{l}\text { Insufficient awareness of health and diseases } \\
\text { (possibly leading to future problems) }\end{array}$ & $5(1.7)$ \\
\hline
\end{tabular}

Note: Only problems with frequency of one or more were included. were more susceptible to the occurrence of dosing problems. There were five factors were found to be significantly associated with drug-use problems, including polypharmacy ( $P=0.027)$, multiple comorbidities $(P=0.035)$, hypertension

Table I I Causes of drug-related problems $(n=289)$

\begin{tabular}{|c|c|c|}
\hline Code & Cause & n (\%) \\
\hline $\mathbf{C I}$ & Drug/dose selection & $125(43.4)$ \\
\hline Cl.I & Inappropriate drug selection & $8(2.8)$ \\
\hline $\mathrm{Cl} .2$ & Inappropriate dosage selection & $7(2.4)$ \\
\hline $\mathrm{Cl} .5$ & $\begin{array}{l}\text { Synergistic/preventive drug required and not } \\
\text { given }\end{array}$ & $3(1.0)$ \\
\hline $\mathrm{Cl} .6$ & Deterioration/improvement of disease state & $\mathrm{I}(0.3)$ \\
\hline $\mathrm{Cl} .8$ & Manifest side effect, no other cause & $106(36.7)$ \\
\hline $\mathbf{C 2}$ & Drug-use process & $3(1.0)$ \\
\hline $\mathrm{C} 2.2$ & Drug underused/underadministered & $\mathrm{I}(0.3)$ \\
\hline $\mathrm{C} 2.3$ & Drug overused/overadministered & $2(0.7)$ \\
\hline C3 & Information & $\mathrm{I}(0.3)$ \\
\hline C3.I & Instructions for use/taking not known & $\mathrm{I}(0.3)$ \\
\hline C4 & Patient/psychological & $24(8.3)$ \\
\hline C4.I & Patient forgets to use/take drug & $7(2.4)$ \\
\hline C4.2 & Patient has concerns with drugs & $6(2.1)$ \\
\hline C4.3 & Patient suspects side effect & $7(2.4)$ \\
\hline C4.4 & Patient unwilling to carry financial costs & $2(0.7)$ \\
\hline C4.6 & Patient unwilling to change drugs & $\mathrm{I}(0.3)$ \\
\hline C4.10 & Patient takes food that interacts with drugs & $\mathrm{I}(0.3)$ \\
\hline C6 & Others & $136(47.1)$ \\
\hline C6.I & Other cause & $2(0.7)$ \\
\hline C6.2 & No obvious cause & $134(46.4)$ \\
\hline
\end{tabular}

Note: Only causes with frequency of one or more were included. 
Table I 2 Factors associated with the occurrence of drug-related problems $(n=200)$

\begin{tabular}{l|l|l}
\hline \multirow{2}{*}{} & \multicolumn{2}{|l}{ Drug-related problems (n=200) } \\
\cline { 2 - 3 } & OR $^{\mathrm{c}}(\mathbf{9 5 \%} \mathbf{C l})$ & $\boldsymbol{P}$-value \\
\hline Elderly & $1.549(0.779-3.078)$ & $0.279^{\mathrm{a}}$ \\
Polypharmacy & $2.956(1.480-5.906)$ & $0.003^{\mathrm{a}, *}$ \\
Multiple comorbidities $(\geq 3)$ & $3.536(1.729-7.23 \mathrm{I})$ & $0.00 \mathrm{I}^{\mathrm{a}, *}$ \\
Hyperlipidemia & $2.656(1.323-5.330)$ & $0.009^{\mathrm{a}, *}$ \\
Hypertension & $1.966(0.992-3.896)$ & $0.075^{\mathrm{a}}$ \\
Type 2 diabetes mellitus & $1.026(0.500-2.106)$ & $>0.999^{\mathrm{a}}$ \\
Osteoarthritis & $2.798(1.108-7.056)$ & $0.040^{\mathrm{a}, *}$ \\
Cardiovascular disease & $2.303(0.764-6.942)$ & $0.170^{\mathrm{b}}$ \\
Renal impairment & - & $0.044^{\mathrm{b}, *}$ \\
Hepatic impairment & $0.907(0.238-3.453)$ & $>0.999^{\mathrm{b}}$ \\
\hline
\end{tabular}

Notes: $* P<0.05$; 'computed using continuity correction; 'computed using Fisher's exact test; ' logistic regression is not applicable for variables with small or empty cells.

$(P=0.011)$, and type 2 diabetes mellitus. For drug interactions, factors that had significant associations with DRPs were elderly $(P=0.049)$, polypharmacy $(P<0.001)$, multiple comorbidities $(P<0.001)$, hyperlipidemia $(P=0.020)$, hypertension $(P<0.001)$, and osteoarthritis $(P=0.013)$. Only type 2 diabetes mellitus was significantly associated with "other" problems.

\section{Discussion}

In this study, the median age of the patient population was 64 years, ranging from 22 to 91 years. This was comparable with a cohort study, which reported on RA patients aged 18-89 years, with a median age of 58 years. ${ }^{27}$ The slight difference in age reported between the studies was probably due to different sample sizes, which was not representative of all the population. The sex ratio was found to be $6: 1$ for females:males in this study. According to a study conducted in Romania, the female:male ratio in RA patients was approximately $5: 1,{ }^{28}$ while another study reported a sex ratio of 2:1. ${ }^{29}$ The higher number of female RA patients could be explained by the fact that women produce a more robust immunoresponse to infection, which may be responsible for the higher risk of developing autoimmune diseases. ${ }^{30}$

This study demonstrated that Sjögren's syndrome was the most common complication, affecting $10 \%$ of the patient population. This finding was consistent with other studies, which reported that the percentage of RA patients who fulfilled the criteria of Sjögren's syndrome ranged from $4 \%$ to $31 \% \cdot{ }^{31,32}$ Hyperlipidemia (56\%), hypertension (55\%), and type 2 diabetes mellitus (33\%) were the three most prevalent comorbidities in this study population. This was similar to a study conducted by the South Korean government that revealed that the most frequently associated comorbidities in RA were hypertension (30.3\%), osteoarthritis (22.6\%), and hyperlipidemia (11.1\%). ${ }^{12}$ Polypharmacy is common among people with RA, and is associated with older age and longer RA duration through a greater number of comorbidities. ${ }^{33}$ Polypharmacy cases found in this study amounted to $64.5 \%$, which was in accordance with a study that found five as the mean number of medications in RA patients. ${ }^{34}$

\section{Drug-related problems}

This is the first study to investigate DRPs among patients with RA. A total of 289 DRPs were identified, with an average of $1.5 \pm 1.0$ problems per patient. A study conducted in Norway yielded 6,158 DRPs detected among 2,465 elderly patients after medication review, with an average of 2.6 DRPs per patient. ${ }^{35}$ Another recent study related to DRPs in erectile dysfunction patients identified 244 DRPs in 200 patients, with an average of 1.2 $\pm 2.1 \mathrm{DRPs}$ in each patient. ${ }^{17}$ Discrepancies between these studies can be due to several factors, such as different interpretations of the problems by researchers, study design, and settings.

In this study, the most frequently encountered DRPs were adverse reactions and drug interactions. Likewise, the study conducted by Ernst et al in patients with musculoskeletal disorder comprising 93 RA patients reported that adverse reactions and need of additional therapy were the two most commonly identified DRPs. ${ }^{15}$ However, discrepancies might occur due to different health care settings and study populations, leading to differential classification of DRPs.

\section{Adverse reactions}

Adverse reactions were the most frequently detected DRPs in this study. Among patients receiving Mtx, approximately $58 \%$ suffered from side effects of the drug. The prevalence of side effects caused by Mtx in this study was greater than that from a study conducted in the Saudi population, which demonstrated that $32.8 \%$ of patients using Mtx experienced at least one adverse event that was preventable. ${ }^{35}$ Hematological side effects were the most prominent in this study, comprising approximately $14 \%$ of all Mtx users. This percentage was slightly higher than another study that found $11.8 \%$ of patients receiving Mtx to be affected..$^{36}$ Gastrointestinal disturbances were also reported as side effects of Mtx, with $12.8 \%$ of patients reporting it. Different studies have had different results on this finding, ranging from $7.0 \%{ }^{37}$ to $52.5 \% .{ }^{35}$ Most cases of hepatic side effects with Mtx in this study involved elevated levels of liver enzymes, found in $10.5 \%$ of the patients. This was similar to the results of a study that revealed that incidence of adverse liver events was $11.2 \%$ in Mtx-treated patients. ${ }^{38}$ 


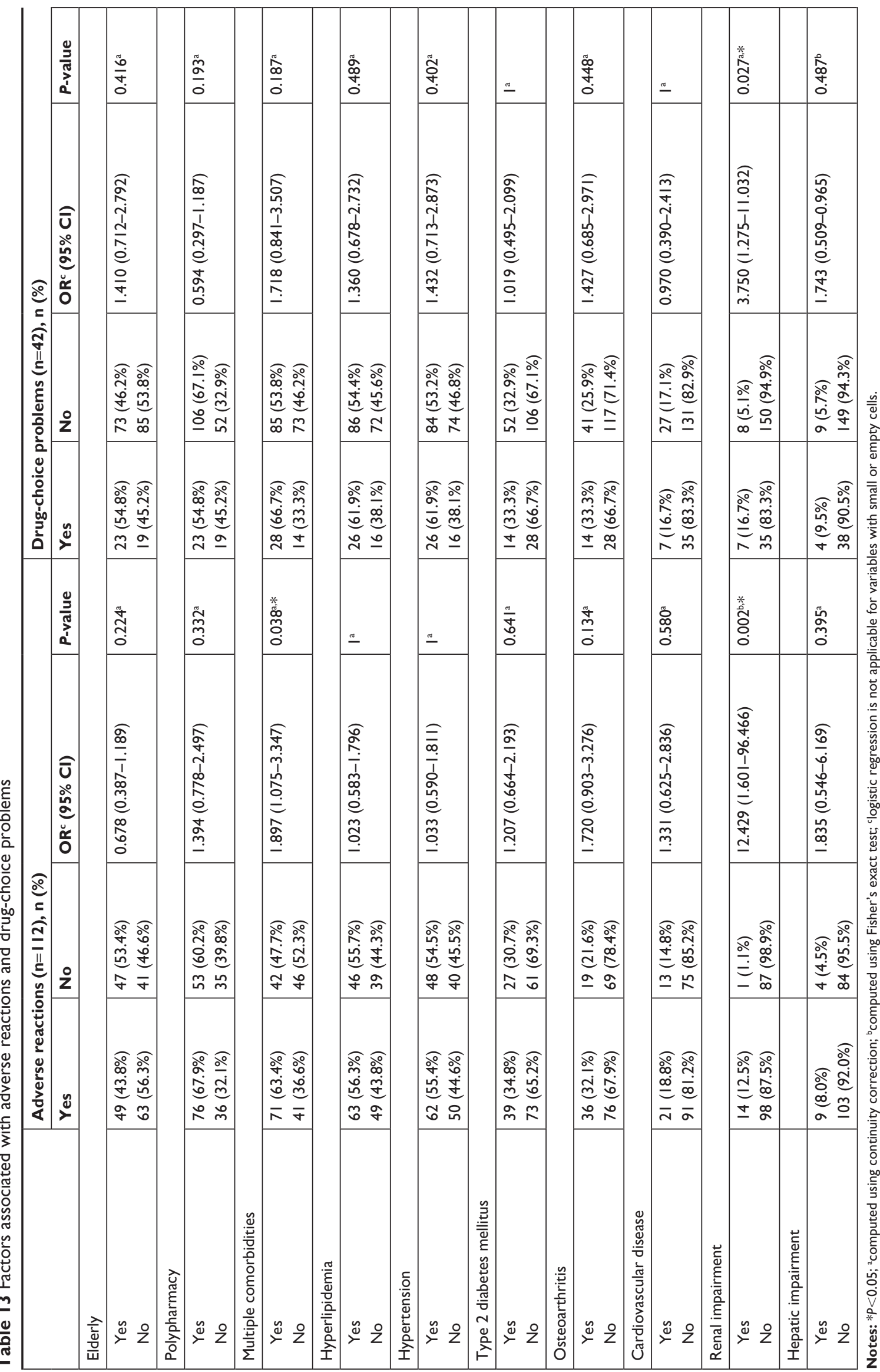




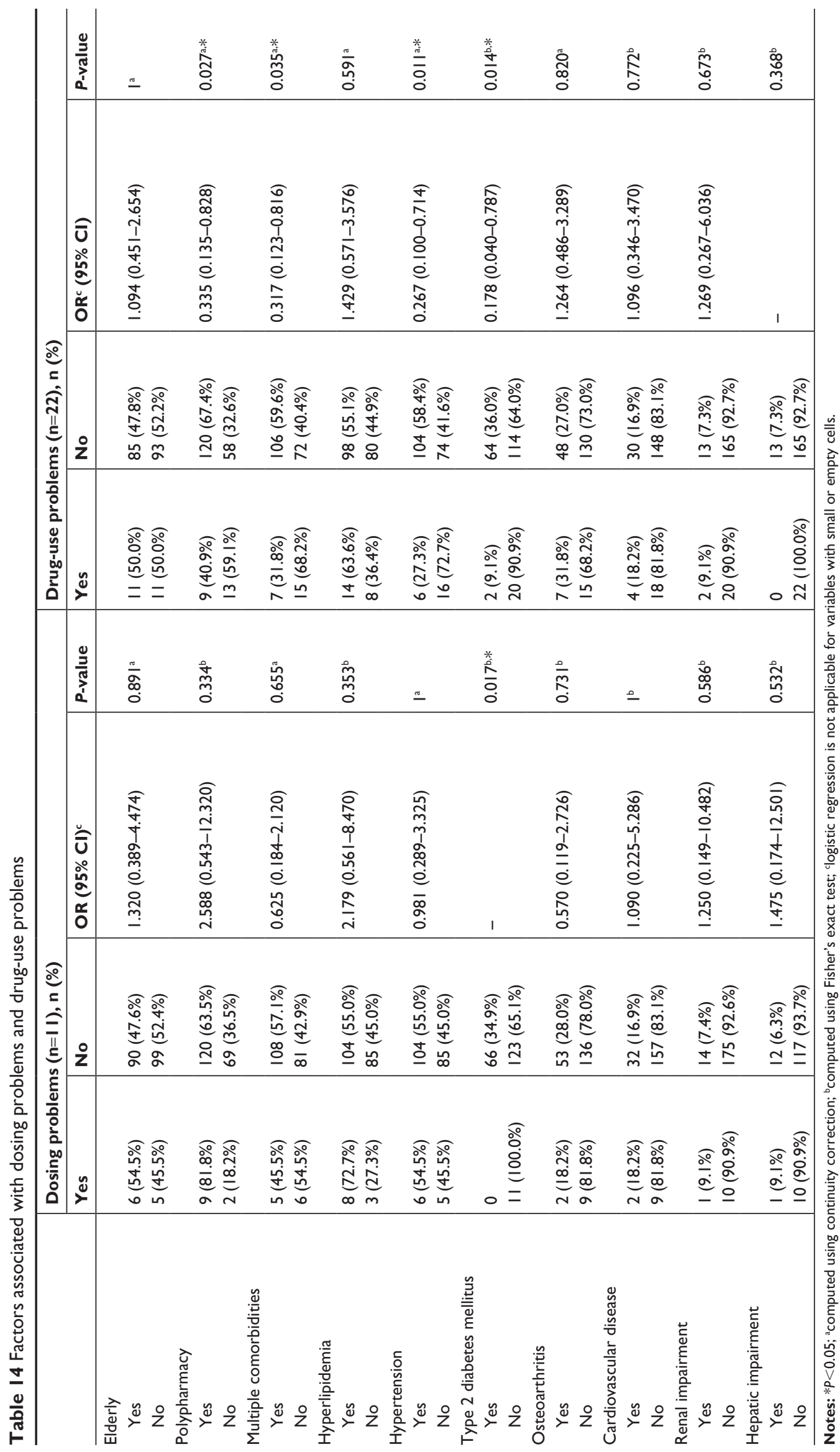




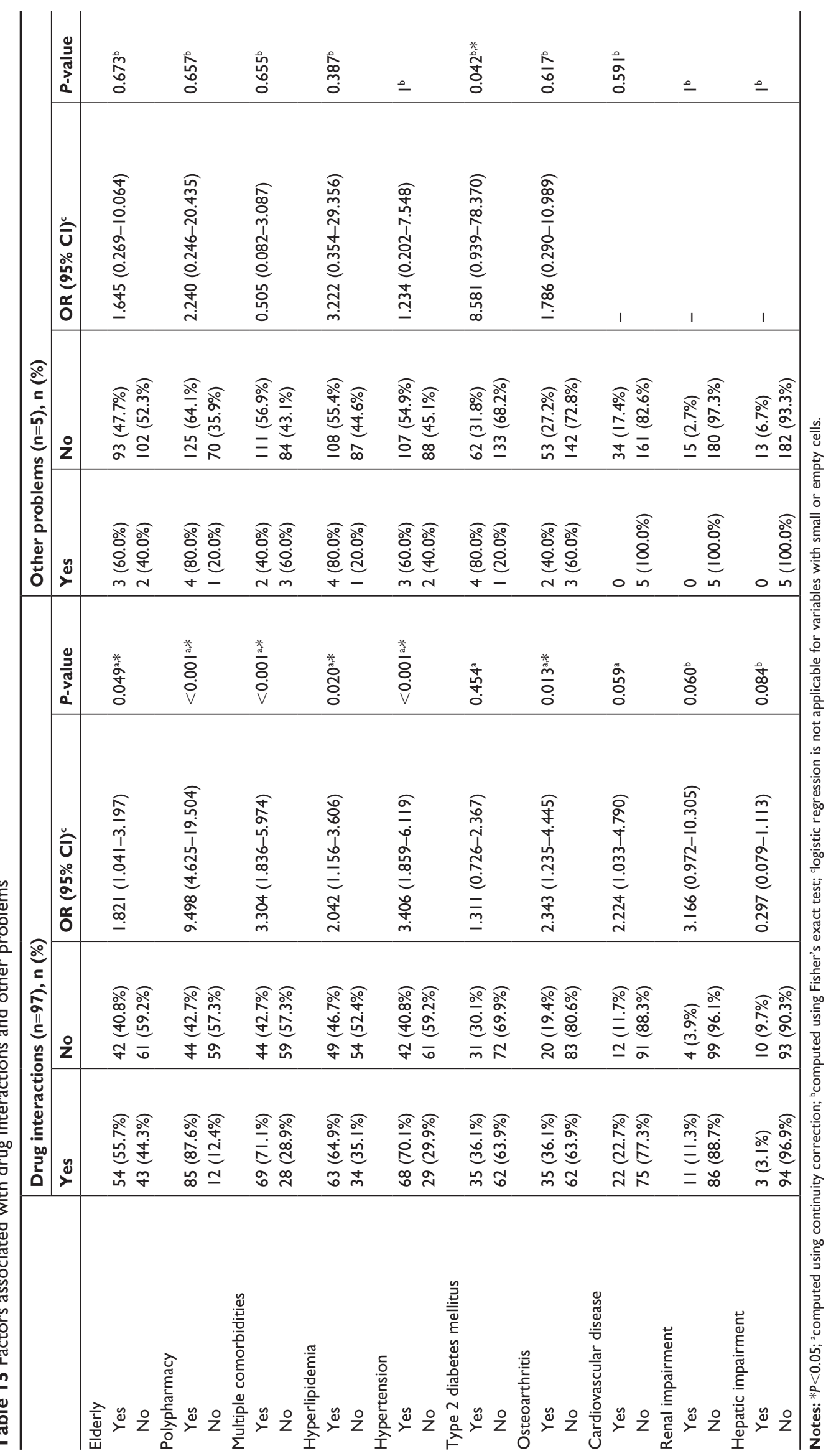


Besides Mtx, other DMARDs, including sulfasalazine, hydroxychloroquine, and leflunomide, shared many of the same potential toxicities as those of Mtx, including cytopenia and hepatotoxicity. ${ }^{39,40}$ However, in this study, side effects reported with the use of sulfasalazine, hydroxychloroquine, and leflunomide were less common, making up only about $20 \%$ of all the adverse reactions reported. A previous study revealed concerns with combination Mtx-leflunomide therapy, which may cause potentially life-threatening side effects, particularly hepatotoxicity and leucopaenia. ${ }^{41}$ However, the adverse effects reported among the studies have not been consistent, as it has been demonstrated that the majority of the side effects seemed to be minor in another study. ${ }^{42}$

Although most patients tolerate Mtx well, monitoring is essential to prevent side effects. ACR guidelines call for monitoring of liver enzymes and blood counts at least every 3 months. ${ }^{43}$ Monitoring frequency can be reduced afterward based on clinical judgment, with consideration of such risk factors as age, comorbidity, and renal impairment.

\section{Drug-choice problems}

Untreated indications comprised $8.7 \%$ of DRPs in this study. This was less than that of a study conducted among Taiwanese older adults, which showed that the proportion of untreated indications was $16 \%-18 \%{ }^{44}$ The majority of the cases were correlated with untreated hyperlipidemia, followed by anemia and hypertension. This was found to be consistent with a study conducted in Japan, which reported that the percentage of untreated hypertension was significantly lower than the percentage of unattended hypercholesterolemia. ${ }^{45}$

In this study, most problems of inappropriate use of drugs were described in updated Beers criteria. ${ }^{46}$ Inappropriate drugs were detected in $4.2 \%$ of cases, a number that was close to that of an Indian study. ${ }^{47}$ However, the result was not in concordance with a study that demonstrated inappropriate drug choice contributed to $8.2 \%$ of all DRPs. ${ }^{48}$ Despite the overall result showing low incidence of drug-choice problems, the need to review medications prescribed to patients is crucial to reduce the risk of inappropriate use so that patients can receive the most suitable drugs, which are safer.

\section{Dosing problems}

Hydroxychloroquine overdose was detected in two cases in this study. The common threshold of $6.5 \mathrm{mg} / \mathrm{kg} / \mathrm{day}$ has been published as the upper limit of safe dosing for hydroxychloroquine ${ }^{49}$ In this study, there was one case in which the dose of hydroxychloroquine prescribed was $400 \mathrm{mg}$ twice per day in a patient weighing $44 \mathrm{~kg}$. There is a higher risk of retinopathy developing in patients receiving hydroxychloroquine at $>6.5 \mathrm{mg} / \mathrm{kg} /$ day, due to toxicity. ${ }^{50}$

In usual conditions, Mtx will be initiated at a dose of 7.5-10 mg per week, and this can be increased to a maximum $25 \mathrm{mg}$ per week. ${ }^{51}$ The low initial dose aims to manage intolerance to oral Mtx and improve adherence to therapy. ${ }^{52}$ However, in this study, there was one case where Mtx was started at $20 \mathrm{mg}$ per week and discontinued later, due to the occurrence of side effects. In clinical practice, step-up strategy is usually applied, where the Mtx dose is increased stepwise, starting at a low and often ineffective dose, and increasing the dose until the treatment target is reached..$^{53}$ However, a study has indicated that there was no difference in the tolerability of Mtx-naïve RA patients when comparing two doses of Mtx: 15 and $25 \mathrm{mg}$ per week. ${ }^{54}$ Discrepancies among the studies reveal that different patients might benefit from different dosing for optimal disease control. There is no guidance on the optimal initiation and maintenance dose of Mtx for individual patients. ${ }^{51}$ Therefore, further studies are encouraged to explore the optimization of Mtx dosing.

\section{Drug-use problems}

In this study, $7.6 \%$ of cases reported drug-use problems, where patients were not compliant to their medications. The majority of the drug-use problems involved RA medications. However, compliance status in this study was not in accordance with that reported in other studies. Muller et al reported that the compliance rate in RA patients was $80 \%$, indicating the noncompliance rate was much greater compared to that in this study. ${ }^{55}$ Forgetfulness and fear of side effects were found to be the common reasons for noncompliance with RA medications, especially Mtx, which was administered on a weekly basis. ${ }^{56}$ Other factors included concern about cost, particularly with leflunomide. ${ }^{57}$ Therefore, reasons for patients' noncompliance should be taken into consideration before further action on the drug regimen. Unrecorded information regarding patients' compliance in the medical records in this study may have led to discrepancies in the reported prevalence between studies. This could have led to underestimation of DRPs.

\section{Drug interactions}

Approximately a third (33.6\%) of the DRPs identified in this study were drug interactions. This result was comparable with a study that revealed that drug-drug interactions were a common cause of medication error, with a prevalence of 
$20 \%-40 \%$, particularly in the elderly, due to polypharmacy. ${ }^{58}$ The majority of potential drug interactions found in this study involved Mtx. This result represented a limiting factor for the use of Mtx during the clinical management of RA, despite its good safety profile, especially when several drugs are coadministered to treat the disease. ${ }^{59}$

Among the drugs interacting with Mtx, omeprazole was found to be the major representative of potential drug interactions identified in this study, with $40.2 \%$ of cases, followed by diclofenac sodium (32\%). Likewise, a study demonstrated that the interaction between Mtx and omeprazole was the most common (29.3\%), with diclofenac sodium next $(17.6 \%) .{ }^{60}$ The interaction was attributed to the delay of renal clearance of Mtx when it was coadministered with proton-pump inhibitors or NSAIDs, thus potentiating its adverse effects. ${ }^{61}$ The association of Mtx and NSAIDs can cause several complications, such as severe hematologic and gastrointestinal toxicity. ${ }^{61}$ Therefore, patients who receive combinations of drugs concurrently should be strictly monitored to avoid complications or side effects due to possible relatively high concentration of Mtx.

The clinical significance of these interactions has not been substantiated by extensive clinical observations. After assessment of benefits and risks, combinations of offending drugs will still be used in certain hospital settings, depending on their prescription policies. Therefore, frequent monitoring should be conducted to minimize adverse effects secondary to drug-drug interactions.

\section{Other problems}

Other problems contributed in the least proportion to DRPs, with all cases identified under insufficient awareness of health and diseases possibly leading to future problems. In this study, there were only five cases where patients had inadequate awareness on RA. This was consistent with a study that showed a majority of RA patients were aware of the occurrence of adverse drug reactions caused by Mtx. ${ }^{62}$ To raise awareness on RA, there was a Rheumatoid Awareness Day held annually on February 2, giving RA patients a day of recognition with the aim of educating about rheumatoid disease. ${ }^{63}$ In this study, however, awareness of the patients might have been overestimated, as patient feedback was not recorded in the medical notes in all.

\section{Causes of DRPs}

The most prevalent cause of DRPs in this study appeared to be "others", followed by "drug or dose selection". When matching causes to problems, most drug interactions were classified into no obvious cause (C6.2) under the domain of "others". For the domain of drug or dose selection, manifestation of side effects with no other cause $(\mathrm{C} 1.8)$ was most frequently associated with such DRPs as adverse reactions of drugs, while the subtypes of inappropriate drug and dose selection (C1.1 and C1.2) were also used to explain DRPs like adverse reactions and drug-choice problems. The assignment of causes to each DRP was based on the researchers' own judgment or information obtained from the medical records, which can lead to difficulties in assessing the causes of DRPs, as some possible causes of DRPs may not be retrievable from medical records.

\section{Factors associated with DRPs Elderly}

In this study, being elderly was not found to be significantly associated with DRPs. This finding was not consistent with several studies suggesting that the prevalence of DRPs is high in the elderly population, as risk increases with age, especially when polypharmacy was one of the risk factors. ${ }^{48,64,65}$ However, findings on the association between age and DRPs are conflicting. There was a local study that had similar finding to this study, demonstrating that the association between being elderly and DRPs was not significant. ${ }^{19}$ Also, Koh et al reported that being elderly did not result in a higher risk of experiencing adverse drug reactions or DRPs. ${ }^{66}$ Discrepancies among the studies suggest further studies need to be carried out to investigate the association between being elderly and the occurrence of DRPs.

\section{Multiple comorbidities}

The prevalence of multimorbidity has been found to be $65 \%-80 \%$ in elderly populations. ${ }^{67}$ In correspondence with other studies, patients who possessed comorbid diseases had a higher risk of encountering DRPs. ${ }^{68}$ Adverse reactions, drug-use problems, and drug interactions were shown to be significantly associated with DRPs in this study, which is supported by a few others. ${ }^{69,70}$ Comparable with another study, patients with comorbidity were three times more susceptible to adverse drug reactions than those without comorbidity. ${ }^{71}$ The high incidence of adverse drug reactions can be explained by the established fact that elderly people are often frail and highly sensitive to pharmacotherapy, due to changes in pharmacokinetic and pharmacodynamic parameters and also impairment in many organ functions. ${ }^{71}$ Since it is inevitable that the majority of elderly patients present with multiple comorbid diseases, it is important to have medication reconciliation in all health care settings to 
avoid medication errors, including inappropriate prescriptions, dosing errors, and drug-drug interactions.

\section{Polypharmacy}

The issue of polypharmacy is a prevalent concern associated with DRPs in the elderly, resulting from multiple comorbidities that require chronic medical therapies. ${ }^{48.72,73}$ As such, it was not surprising that polypharmacy was found to be significantly associated with the occurrence of DRPs in this study. In agreement with a few studies, it was strongly supported that an increase in medications prescribed posed an elevated risk of medication errors, which in turn lead to DRPs. ${ }^{74}$ Strong associations between polypharmacy and drug-use problems was supported by a study that reported that polypharmacy influenced medication adherence negatively, with high noncompliance status, which was increased with the number of medication prescribed. ${ }^{24}$ High incidence of drug-use problems could be justified by the complexity of drug regimens in polypharmacy and cognitive impairment of the elderly. ${ }^{75}$ Therefore, pharmacists play an important role in the optimization of drug treatment for the patient's benefit. More efforts should be put into medication review to minimize polydrug therapy whenever possible to reduce the risk of DRPs.

\section{Osteoarthritis}

In this study, osteoarthritis was found to have significant association with DRPs. Across the problem domains, RA patients with comorbid osteoarthritis were more prone to acquire drug interactions. This finding corresponds to a study that demonstrated that the risk of drug interactions was high in osteoarthritis patients, with a few clinically significant interactions that prompted a recommendation for avoidance. ${ }^{76}$ NSAIDs were commonly used by older patients with osteoarthritis, but were associated with many adverse events, resulting in negative likelihood of NSAID continuation in osteoarthritis patients. ${ }^{77,78}$ However, this is not comparable with the findings in this study, which revealed that osteoarthritis was significantly associated only with drug interactions, whereas correlation with other problem domains like adverse reactions was not detected. The discrepancies are most probably due to the small sample, involving a limited number of patients with osteoarthritis among RA patients.

\section{Hypertension}

Studies have demonstrated that patients with hypertension are associated with higher risk of DRPs. ${ }^{79,80}$ However, findings from the literature review were in contradiction to those in this study. Hypertension was not significantly associated with DRPs, but showed strong correlation with drug interactions and drug-use problems in term of problem domains. The high risk of drug interaction could be explained by the use of antihypertensive drugs, particularly calcium-channel blockers, which commonly interact with $\alpha$-blockers and statins. ${ }^{81}$ This result was not consistent with that of research done in east Ethiopia, which stated drug interactions in hypertension patients were most commonly caused by angiotensinconverting enzyme inhibitors. ${ }^{82}$ This difference may be due to the variation in commonly prescribed medications in the two countries.

\section{Type 2 diabetes mellitus}

In the present study, patients with type 2 diabetes mellitus were found to be at lower risk of having DRPs. This result was not consistent with the findings of other studies, which revealed a higher risk of DRPs in patients with diabetes. ${ }^{79}$ Likewise, two local studies done on DRPs in patients with diabetes mellitus also demonstrated that $90.5 \%$ and $91.8 \%$ of patients had at least one DRP. ${ }^{19,83}$ This conflict with other studies may be due to the limited sample size of diabetic patients in this study, which was not representative of all the population.

\section{Renal impairment}

Renal impairment was found to be significantly associated with the occurrence of DRPs in this study. Consistently, a study conducted in Canada revealed that DRPs are prevalent among CKD patients. ${ }^{84}$ Among the six domains of DRPs, adverse reactions and drug-choice problems were found to be significantly associated with DRPs in the present study. This result was in line with an Indonesian study that demonstrated that treatment-effectiveness and adverse-reaction domains contributed to the majority of DRPs in CKD patients. ${ }^{85}$ Therefore, identification and prevention of DRPs are vital measures, in order to improve clinical outcomes in CKD patients who are prone to encounter DRPs.

\section{Limitations of the study}

There is a risk of bias attributed to the retrospective nature of this study, because the assessment of DRPs was dependent solely on patients' clinical records as the source of data. This may have caused an underestimation of prevalence of some important data, including physicians' and patients' perceptions, which could not be retrieved from the medical records. Adverse reactions were diagnosed mainly by clinical suspicion and interpreted from clinical findings and history. 
As such, the association between the drugs and adverse reactions could not be completely verified.

\section{Conclusion}

Among all the RA medications, Mtx was the most commonly used as first-line treatment. csDMARD monotherapy was the most frequently prescribed compared to double- and tripleDMARD therapy. Biological DMARDs were rarely used, as they were prescribed only when csDMARDs had failed or patients were intolerant to csDMARDs. Concurrent medications that were most frequently implicated in this study were statins, which corresponded with hyperlipidemia as the most common comorbidity. The most commonly identified DRPs were adverse reactions, drug interactions, and drug-choice problems. On the other hand, several factors were found to be significantly associated with the occurrence of DRPs, including polypharmacy, multiple comorbidities, hyperlipidemia, osteoarthritis, and renal impairment. Therefore, early identification of the types and patterns of DRPs, as well as the factors associated with them, is important to enhance the prevention and management of DRPs in RA patients.

\section{Acknowledgments}

The authors would like to thank the University of Malaya, Malaysia, and University of Malaya Medical Center for technical support.

\section{Disclosure}

The authors report no conflicts of interest in this work.

\section{References}

1. Fleischmann R, Kremer J, Cush J, et al. Placebo-controlled trial of tofacitinib monotherapy in rheumatoid arthritis. $N$ Engl J Med. 2012; 367(6):495-507.

2. Knevel R, Huizinga TWJ, Kurreeman F. Genomic influences on susceptibility and severity of rheumatoid arthritis. Rheum Dis Clin North Am. 2017;43(3):347-361.

3. Rudan I, Sidhu S, Papana A, et al. Prevalence of rheumatoid arthritis in low- and middle-income countries: a systematic review and analysis. J Glob Health. 2015;5(1):010409.

4. Gibofsky A. Epidemiology, pathophysiology, and diagnosis of rheumatoid arthritis: a synopsis. Am J Manag Care. 2014;20(7 Suppl): S128-S135

5. Brunier L, Bleterry M, Merle S, et al. Prevalence of rheumatoid arthritis in the French West Indies: results of the EPPPRA study in Martinique. Joint Bone Spine. 2017;84(4):455-461.

6. National Institute of Arthritis and Musculoskeletal and Skin Diseases (NIAMS). Rheumatoid arthritis; 2014. Available from: https://storage. googleapis.com/quantumunitsed-com/materials/1700_What-isRheumatoid-Arthritis.pdf. Accessed December 21, 2017.

7. Cojocaru M, Im C, Silosi I, Vrabie CD, Tanasescu R. Extra-articular manifestations in rheumatoid arthritis. Mcedica. 2010;5(4):286-291.

8. Burmester GR, Pope JE. Novel treatment strategies in rheumatoid arthritis. Lancet. 2017;389(10086):2338-2348.
9. Dougados M, Soubrier M, Antunez A, et al. Prevalence of comorbidities in rheumatoid arthritis and evaluation of their monitoring: results of an international, cross-sectional study (COMORA). Ann Rheum Dis. 2014;73(1):62-68.

10. Liao KP. Cardiovascular disease in patients with rheumatoid arthritis. Trends Cardiovasc Med. 2017;27(2):136-140.

11. Michaud K, Wolfe F. Comorbidities in rheumatoid arthritis. Best Pract Res Clin Rheumatol. 2007;21(5):885-906.

12. Jeong H, Baek SY, Kim SW, et al. Comorbidities of rheumatoid arthritis: results from the Korean national Health and Nutrition Examination Survey. PLoS One. 2017;12(4):e0176260.

13. Ranganath VK, Maranian P, Elashoff DA, et al. Comorbidities are associated with poorer outcomes in community patients with rheumatoid arthritis. Rheumatology. 2013;52(10):1809-1817.

14. Pharmaceutical Care Network Europe Foundation (PCNE). PCNE classification for drug related problems version 5.01. 2006. Available from: http://www.pcne.org/sig/drp/documents/PCNE\%20classification $\% 20$ V5.01.pdf. Accessed December 18, 2017.

15. Ernst ME, Iyer SS, Doucette WR. Drug-related problems and quality of life in arthritis and low back pain sufferers. Value Health. 2003;6(1): $51-58$.

16. Treharne GJ, Douglas KM, Iwaszko J, et al. Polypharmacy among people with rheumatoid arthritis: the role of age, disease duration and comorbidity. Musculoskeletal Care. 2007;5(4):175-190.

17. Huri HZ, Ling CF, Razack AH. Drug-related problems in patients with erectile dysfunctions and multiple comorbidities. Ther Clin Risk Manag. 2017;13:407-419

18. Zaman Huri H, Hui Xin C, Sulaiman CZ. Drug-related problems in patients with benign prostatic hyperplasia: a cross sectional retrospective study. PLoS One. 2014;9(1):e86215.

19. Zaman Huri H, Fun Wee H. Drug related problems in type 2 diabetes patients with hypertension: a cross-sectional retrospective study. BMC Endocr Disord. 2013;13:2.

20. Stefanski AL, Tomiak C, Pleyer U, Dietrich T, Rüdiger Burmester G, Dörner T. The diagnosis and treatment of sjögren's syndrome. Deutsch Ärzteb Int. 2017;114(20):354-361.

21. Hurn SE, Vicenzino BT, Smith MD. Non-surgical treatment of hallux valgus: a current practice survey of Australian podiatrists. J Foot Ankle Res. 2016;9:16.

22. Richeldi L, Collard HR, Jones MG. Idiopathic pulmonary fibrosis. Lancet. 2017;389(10082):1941-1952.

23. World Health Organization (WHO). Elderly population; 2018. Available from: http://www.who.int/healthinfo/survey/ageingdefnolder/en. Accessed April 13, 2018.

24. Cantlay A, Glyn T, Barton N. Polypharmacy in the elderly. InnovAiT. 2016;9(2):69-77.

25. International Society of nephrology (ISN). KDIGO clinical practice guideline for acute kidney injury. Official J Int Soc Nephrol. 2018;2(1):1-15.

26. Chtioui H, Buclin T. Pharmacokinetics in hepatic impairment: mind the protein binding. $J$ Hepatol. 2015;63(6):1539-1540.

27. Innala L, Berglin E, Möller B, et al. Age at onset determines severity and choice of treatment in early rheumatoid arthritis: a prospective study. Arthritis Res Ther. 2014;16(2):R94.

28. Cristina S, Lucian P, Elvira C, Maria S. Sex ratio and age in patients with rheumatoid arthritis: data from a cohort in south-east Romania. Rom J Rheumatol. 2015;24(4):220-225.

29. Almeida MS, Almeida JV, Bertolo MB. [Demographic and clinical features of patients with rheumatoid arthritis in Piauí, Brazil - evaluation of 98 patients]. Rev Bras Reumatol. 2014;54(5):360-365. Portuguese.

30. Brunelleschi S. Immune response and auto-immune diseases: gender does matter and makes the difference. IJGSM. 2016;2(1):5-14.

31. Hajiabbasi A, Shenavar Masooleh I, Alizadeh Y, Banikarimi AS, Ghavidel Parsa P. Secondary Sjogren's syndrome in 83 patients with rheumatoid arthritis. Acta Med Iran. 2016;54(7):448-453.

32. Antero DC, Parra AG, Miyazaki FH, Gehlen M, Skare TL. Secondary Sjögren's syndrome and disease activity of rheumatoid arthritis. Rev Assoc Med Bras. 2011;57(3):319-322. 
33. Vallejo AA, Rutherforda, Filkova M, et al. Polypharmacy is associated with an increased risk of adverse outcomes in patients with rheumatoid arthritis. Ann Rheum Dis. 2017;76(Suppl 2):806.

34. Filkova M, Carvalho J, Norton S, et al. Polypharmacy and unplanned hospitalizations in patients with rheumatoid arthritis. J Rheumatol. 2017;44(12):1786-1793

35. Al-Malaq HM, Al-Arfaj HF, Al-Arfaj AS. Adverse drug reactions caused by methotrexate in Saudi population. Saudi Pharm J. 2012; 20(4):301-305.

36. Gilani ST, Khan DA, Khan FA, Ahmed M. Adverse effects of low dose methotrexate in rheumatoid arthritis patients. $J$ Coll Physicians Surg Pak. 2012;22(2):101-104.

37. Dubey L, Chatterjee S, Ghosh A. Hepatic and hematological adverse effects of long-term low-dose methotrexate therapy in rheumatoid arthritis: an observational study. Indian J Pharmacol. 2016;48(5):591-594.

38. Low C, Low C, Coughlan RJ, O'Donnell MJ, Carey JJ. Risk of liver injury among methotrexate users: a meta-analysis of randomised controlled trials. Semin Arthritis Rheum. 2015;45(2):156-162.

39. Heidari R, Rasti M, Shirazi Yeganeh B, Niknahad H, Saeedi A, Najibi A. Sulfasalazine-induced renal and hepatic injury in rats and the protective role of taurine. Bioimpacts. 2016;6(1):3-8.

40. Ruderman EM. Overview of safety of non-biologic and biologic DMARDs. Rheumatology. 2012;51(Suppl 6):vi37-vi43.

41. Hodkinson B, Magomero KR, Tikly M. Combination leflunomide and methotrexate in refractory rheumatoid arthritis: a biologic sparing approach. Ther Adv Musculoskelet Dis. 2016;8(5):172-179.

42. Londono J, Santos AM, Santos PI, Cubidez MF, Guzman C, ValleOnate R. Therapeutic efficacy and safety of methotrexate + leflunomide in Colombian patients with active rheumatoid arthritis refractory to conventional treatment. Rev Bras Reumatol. 2012;52(6):837-845.

43. Louis BS, Timothy M. American College of rheumatology guideline for the treatment of rheumatoid arthritis. Arthritis Care Res. 2016;68(1): $1-252015$

44. Chan DC, Chen JH, Wen CJ, Chiu LS, Wu SC. Effectiveness of the medication safety review clinics for older adults prescribed multiple medications. J Formos Med Assoc. 2014;113(2):106-113.

45. Egan BM, Li J, Qanungo S, Wolfman TE. Blood pressure and cholesterol control in hypertensive hypercholesterolemic patients: NHANES 1988-2010. Circulation. 2013;128(1):29-41.

46. American Geriatrics Society (AGS). American Geriatrics Society 2015 updated Beers criteria for potentially inappropriate medication use in older adults. J Am Geriatr Soc. 2015;60(4):616-631.

47. Rambhade S, Chakarborty A, Shrivastava A, Patil UK, Rambhade A A survey on polypharmacy and use of inappropriate medications Toxicol Int. 2012;19(1):68-73.

48. Ahmad A, Mast MR, Nijpels G, Elders PJ, Dekker JM, Hugtenburg JG. Identification of drug-related problems of elderly patients discharged from hospital. Patient Prefer Adherence. 2014;8:155-165.

49. Browning DJ. The prevalence of hydroxychloroquine retinopathy and toxic dosing, and the role of the ophthalmologist in reducing both. Am J Ophthalmol. 2016;166:ix-xi.

50. Paulose R, Chhablani J, Jhingan M. Update on hydroxychloroquine retinopathy. Kerala J Ophthalmol. 2017;29(1):9-13.

51. Bello AE, Perkins EL, Jay R, Efthimiou P. Recommendations for optimizing methotrexate treatment for patients with rheumatoid arthritis. Open Access Rheumatol. 2017;9:67-79.

52. Ćalasan MB, van den Bosch OF, Creemers MC, et al. Prevalence of methotrexate intolerance in rheumatoid arthritis and psoriatic arthritis. Arthritis Res Ther. 2013;15(6):R217.

53. Nair SC, Jacobs JW, Bakker MF, et al. Determining the lowest optimally effective methotrexate dose for individual RA patients using their dose response relation in a tight control treatment approach. PLoS One. 2016; 11(3):e0148791

54. Hobl EL, Mader RM, Jilma B, et al. A randomized, double-blind, parallel, single-site pilot trial to compare two different starting doses of methotrexate in methotrexate-naïve adult patients with rheumatoid arthritis. Clin Ther. 2012;34(5):1195-1203.
55. de Cuyper E, de Gucht V, Maes S, van Camp Y, de Clerck LS. Determinants of methotrexate adherence in rheumatoid arthritis patients. Clin Rheumatol. 2016;35(5):1335-1339.

56. Marengo MF, Suarez-Almazor ME. Improving treatment adherence in patients with rheumatoid arthritis: what are the options? Int J Clin Rheumtol. 2015;10(5):345-356.

57. Joplin S, van der Zwan R, Joshua F, Wong PKK. Medication adherence in patients with rheumatoid arthritis: the effect of patient education, health literacy, and musculoskeletal ultrasound. Biomed Res Int. 2015; 2015(9):1-10.

58. Palleria C, Di Paolo A, Giofrè C, et al. Pharmacokinetic drug-drug interaction and their implication in clinical management. J Res Med Sci. 2013;18(7):601-610.

59. Patanè $\mathrm{M}$, Ciriaco $\mathrm{M}$, Chimirri $\mathrm{S}$, et al. Interactions among low dose of methotrexate and drugs used in the treatment of rheumatoid arthritis. Adv Pharmacol Sci. 2013;2013(7):1-8.

60. Bagatini F, Blatt CR, Maliska G, et al. Potential drug interactions in patients with rheumatoid arthritis. Rev Bras Reumatol. 2011;51(1) 29-39

61. Hall JJ, Bolina M, Chatterley T, Jamali F. Interaction between low-dose methotrexate and nonsteroidal anti-inflammatory drugs, penicillins, and proton pump inhibitors. Ann Pharmacother. 2017;51(2):163-178.

62. Cuschieri K, Grech L, Aquilina D, et al. Assessing the awareness of rheumatoid arthritis patients on the occurrence of adverse drug reactions caused by methotrexate. Rheumatology. 2014;53(Suppl 1):i155.

63. Rheumatoid patient Foundation. Rheumatoid awareness day; 2013. Available from: http://rawarrior.com/first-awareness-day-for-rheumatoidarthritis-established-by-rheumatoid-patient-foundation. Accessed April 13, 2018.

64. Peterson C, Gustafsson M. Characterisation of drug-related problems and associated factors at a clinical pharmacist service-naïve hospital in northern Sweden. Drugs Real World Outcomes. 2017;4(2):97-107.

65. Ramanath K, Nedumballi S. Assessment of medication-related problems in geriatric patients of a rural tertiary care hospital. J Young Pharm. 2012;4(4):273-278.

66. Koh Y, Kutty FB, Li SC. Drug-related problems in hospitalized patients on polypharmacy: the influence of age and gender. Ther Clin Risk Manag. 2005;1(1):39-48.

67. Divo MJ, Martinez CH, Mannino DM. Ageing and the epidemiology of multimorbidity. Eur Respir J. 2014;44(4):1055-1068.

68. Ferrández O, Grau S, Urbina O, Mojal S, Riu M, Salas E. Validation of a score to identify inpatients at risk of a drug-related problem during a 4-year period. Saudi Pharm J. 2018;26(5):703-708.

69. Lampropoulos CE, Orfanos P, Bournia VK, et al. Adverse events and infections in patients with rheumatoid arthritis treated with conventional drugs or biologic agents: a real world study. Clin Exp Rheumatol. 2015; 33(2):216-224.

70. Nobili A, Garattini S, Mannucci PM. Multiple diseases and polypharmacy in the elderly: challenges for the internist of the third millennium. J Comorb. 2011;1:28-44.

71. Bassi PU, Osakwe AI, Ogar CK, et al. Impact of comorbidity on adverse drug reaction profile in a cohort of patients treated with artemisinin combination therapies for uncomplicated malaria in Nigeria. Pharmacol Res Perspect. 2017;5(2):e00302.

72. Da Costa FA, Silvestre L, Periquito C, et al. Drug-related problems identified in a sample of Portuguese institutionalised elderly patients and pharmacists' interventions to improve safety and effectiveness of medicines. Drugs Real World Outcomes. 2016;3(1):89-97.

73. Garcia-Caballos M, Ramos-Diaz F, Jimenez-Moleon JJ, BuenoCavanillas A. Drug-related problems in older people after hospital discharge and interventions to reduce them. Age Ageing. 2010;39(4): $430-438$.

74. Maher RL, Hanlon JT, Hajjar ER. Clinical consequences of polypharmacy in elderly. Expert Opinion On Drug Safety. 2014;13(1):10.

75. Zelko E, Klemenc-Ketis Z, Tusek-Bunc K. Medication adherence in elderly with polypharmacy living at home: a systematic review of existing studies. Mater Sociomed. 2016;28(2):129-132. 
76. Dumbreck S, Flynn A, Nairn M, et al. Drug-disease and drug-drug interactions: systematic examination of recommendations in $12 \mathrm{UK}$ national clinical guidelines. BMJ. 2015;350:h949.

77. Zhang W, Ouyang H, Dass CR, Xu J. Current research on pharmacologic and regenerative therapies for osteoarthritis. Bone Res. 2016;4:15040.

78. Laba TL, Brien JA, Fransen M, Jan S. Patient preferences for adherence to treatment for osteoarthritis: the medication decisions in osteoarthritis study (MEDOS). BMC Musculoskelet Disord. 2013;14(1):160.

79. Kovačević SV, Miljković B, Ćulafić M, et al. Evaluation of drug-related problems in older polypharmacy primary care patients. J Eval Clin Pract. 2017;23(4):860-865.

80. Abu R, Basheti I, Abu H, Alsaleh A, Aburuz S. Assessment of drugrelated problems and their impact on blood pressure control in patients with hypertension. Eur J Hosp Pharm. 2015;23(3):995.

81. Wang YC, Hsieh TC, Chou CL, Wu JL, Fang TC. Risks of adverse events following coprescription of statins and calcium channel blockers: a nationwide population-based study. Medicine. 2016;95(2):e2487.
82. Hussein M, Lenjisa JL, Woldu MA, et al. Assessment of drug related problems among hypertensive patients on follow up in adama hospital medical college, East Ethiopia. Clin Pharmacol Biopharm. 2014; 3(2):122.

83. Zaman Huri H, Chai Ling L. Drug-related problems in type 2 diabetes mellitus patients with dyslipidemia. BMC Public Health. 2013; 13(1):1192.

84. Quintana-Bárcena P, Lord A, Lizotte A, Berbiche D, Lalonde L. Prevalence and management of drug-related problems in chronic kidney disease patients by severity level: a subanalysis of a cluster randomized controlled trial in community pharmacies. J Manag Care Spec Pharm. 2018;24(2):173-181.

85. Hesty U. Drug-related problems in chronic kidney disease patients in an Indonesian Hospital. Int J Pharm Pharm Sci. 2016;12(8):298-302.
Therapeutics and Clinical Risk Management

\section{Publish your work in this journal}

Therapeutics and Clinical Risk Management is an international, peerreviewed journal of clinical therapeutics and risk management, focusing on concise rapid reporting of clinical studies in all therapeutic areas, outcomes, safety, and programs for the effective, safe, and sustained use of medicines. This journal is indexed on PubMed Central, CAS,

\section{Dovepress}

EMBase, Scopus and the Elsevier Bibliographic databases. The manuscript management system is completely online and includes a very quick and fair peer-review system, which is all easy to use. Visit http://www.dovepress.com/testimonials.php to read real quotes from published authors.

Submit your manuscript here: http://www.dovepress.com/therapeutics-and-clinical-risk-management-journal 